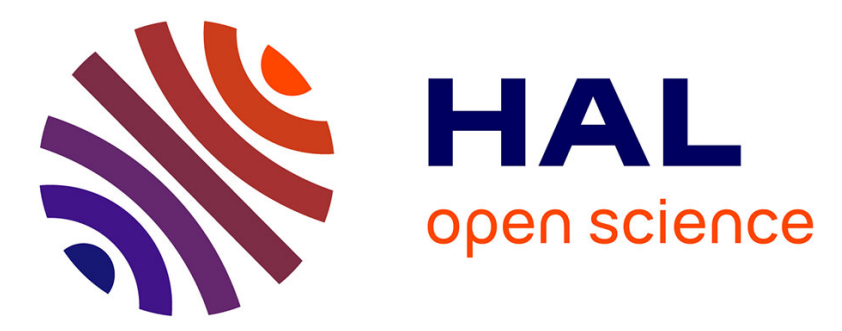

\title{
Earthquake risk in reinforced concrete buildings during aftershock sequences based on period elongation and operational earthquake forecasting
}

Konstantinos Trevlopoulos, Philippe Guéguen, Agnès Helmstetter, Fabrice Cotton

\section{To cite this version:}

Konstantinos Trevlopoulos, Philippe Guéguen, Agnès Helmstetter, Fabrice Cotton. Earthquake risk in reinforced concrete buildings during aftershock sequences based on period elongation and operational earthquake forecasting. Structural Safety, 2020, 84, 10.1016/j.strusafe.2020.101922 . hal-03025682

\section{HAL Id: hal-03025682 https://hal.science/hal-03025682}

Submitted on 26 Nov 2020

HAL is a multi-disciplinary open access archive for the deposit and dissemination of scientific research documents, whether they are published or not. The documents may come from teaching and research institutions in France or abroad, or from public or private research centers.
L'archive ouverte pluridisciplinaire $\mathbf{H A L}$, est destinée au dépôt et à la diffusion de documents scientifiques de niveau recherche, publiés ou non, émanant des établissements d'enseignement et de recherche français ou étrangers, des laboratoires publics ou privés. 


\title{
Earthquake risk in reinforced concrete buildings during aftershock sequences based on period elongation and operational earthquake forecasting
}

\author{
Konstantinos Trevlopoulosa,*, Philippe Guéguena, Agnès Helmstettera, Fabrice Cotton ${ }^{\mathrm{b}}$ \\ a Institut des Sciences de la Terre (ISTerre), Université Grenoble Alpes/Université Savoie Mont-Blanc/CNRS/IRD/IFSTTAR, CS40700, 38058 Grenoble CEDEX 9, France \\ b German Research Center for Geosciences (GFZ), Helmholtz Centre, Potsdam, Germany
}

\section{Keywords:}

Aftershock sequence Cumulative damage

Seismic vulnerability

Time-variant damage state probability

Building tagging

\begin{abstract}
Rapid post-earthquake damage assessment is critical to short-term earthquake crisis management. Reinforced concrete buildings may accumulate damage during an aftershock sequence, and short-term damage forecasts after the mainshock can aid in decision-making (in particular, on whether to allow immediate occupancy) before further damage actually occurs. This paper presents an operative damage forecasting and building tagging procedure for reinforced concrete buildings during synthetic aftershock sequences near Thessaloniki, Greece, for two hypothetical earthquake scenarios. The synthetic aftershock sequences are simulated, and the time-variant seismic vulnerability is modeled based on fragility curves for the damage state thresholds in terms of period elongation. Period elongation is chosen as a damage proxy because it is available for rapid damage assessment in buildings with permanent monitoring systems or for city-scale post-earthquake surveys. Time-variable damage state probabilities owing to aftershocks are estimated, and a building tagging scheme is proposed based on a trafficlight concept (red-orange-green) to assist in seismic crisis management during aftershock sequences.
\end{abstract}

\section{Introduction}

Appropriate decision-making after a major earthquake is important for enabling short-term decisions, such as those regarding building evacuation or repair. Furthermore, seismic crisis management and safety measures can be improved by combining rapid building damage assessment with shortterm forecasting of the seismicity and associated risks [1]. On an urban scale or in the case of critical structures, performance levels related to immediate occupancy or damage grades should be considered in the short-term forecasting. Specifically, a rapid risk assessment must be extended over the entire duration of the aftershock sequence to consider potential damage accumulations owing to the aftershocks [2]. Operative procedures are then required to combine aftershock occurrence forecasts, models of damage accumulation, and building health characterizations with respect to targeted levels of damage. Earthquake risk forecasts during an aftershock sequence are often based on operational earthquake forecasting (OEF). Hermann et al. [3] used OEF to forecast the time-varying seismic risk during an earthquake sequence scenario simulating the 1356 Basel earthquake. They estimated the human losses and associated risks in the short-term to support decisions such as evacuation or the interruption of critical operations in reinforced concrete (RC) buildings. Chioccarelli and Iervolino [4] used OEF to perform a retrospective analysis of loss assessments for aftershock sequences in Italy.

Decision-making in seismic emergencies must consider the increased vulnerability owing to mainshock damage, in addition to the time-variant vulnerability of buildings in view of probable aftershock damage accumulations. Probabilistic frameworks have been developed to assess the contributions of aftershock damage accumulation with respect to the damage caused by the mainshock [5-7]. Furthermore, approaches based on the Markov Chain have been used to assess seismic performance and to develop models for damage accumulation [8-10], in combination with a probabilistic assessment of aftershock occurrence. Most studies report a large contribution of aftershocks in consequence and loss forecasting. The short-term variability of buildings' vulnerabilities, as related to the damage accumulated over the entire seismic sequence, is a key element to be assessed for short-term decision-making.

Monitoring the elongation of the fundamental period of buildings can help assess earthquake damage in buildings whose stiffness gradually degrades before failure [11]. The fundamental period (or frequency) is assumed to be a proxy for the apparent structural stiffness and structural health [12-16]. For instance, the residual stiffness of masonry buildings from period measurements has been used to study the effect of seismic damage accumulation on a macro-seismic intensity assessment [12]. Michel et al. [13] used laboratory tests to quantify the fundamental frequency shift for unreinforced masonry specimens as a function of the structural drift and the level of damage. Experimental and numerical approaches have found empirical relationships between the frequency shift and damage index for RC buildings [14]. Katsanos et al. [15] showed that the transient period elongation during a seismic response did not exceed 1.2 and 1.7 for a designed earthquake and twice the designed earthquake, respectively. Katsanos and Sextos [16] also showed the sufficiency (i.e., independence from magnitude and distance) of the structural period elongation in damage prediction using single-degree-of-freedom oscillators. Reuland et al. [11] predicted fragility curves for subsequent earthquakes based on a measured postearthquake structural frequency and a visual inspection. Masi and Vona [17] reported a $40-50 \%$ period elongation in laboratory-scaled specimens of RC buildings without masonry infills under strong motion. They also reported a $15-30 \%$ period elongation for site-monitored RC buildings with masonry infills subjected to moderate seismic ground motion. Numerical studies indicate that the period corresponding to a collapse threshold is sensitive to p-delta effects [18]. Regarding the aftershock collapse assessment, the maximum inter-story, roof, and residual inter-story drifts appear to be suitable as damage measures [19]. Nevertheless, building tagging procedures often assign a red tag to buildings that have sustained heavy damage without collapsing and those that are considered unsafe, unrepairable, or not worth repairing. In this respect, the procedures herein concern the probabilities of damage states up to heavy damage, based on the period of elongation observed before collapse.

Clinton et al. [20] and Astorga et al. [21] showed the cumulative effects of successive earthquakes on the frequency drop in relation to the amplitude of seismic loading in the context of long-term structural monitoring. Furthermore, Gallipoli et al. [22] reported a co-seismic frequency drop in permanently monitored buildings during mainshocks and after-

* Corresponding author. Present address: French Alternative Energies and Atomic Energy Commission (CEA), 13108 St Paul lez Durance CEDEX, France.

E-mail addresses: konstantinos.trevlopoulos@cea.fr (K. Trevlopoulos), philippe.gueguen@univ-grenoble-alpes.fr (P. Gueguen). 

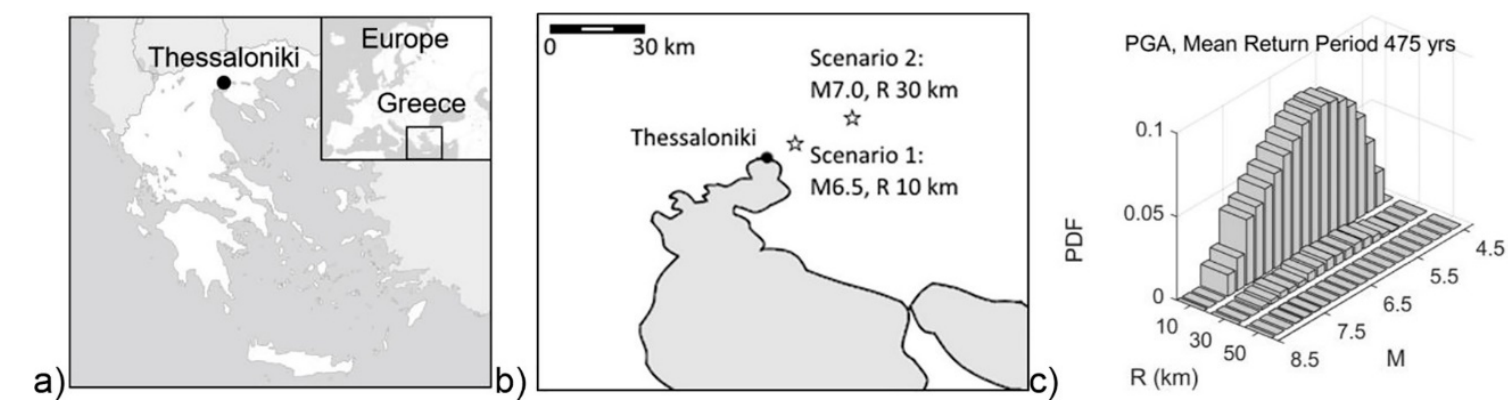

Figure 1. a) Location of study site; b) earthquake scenarios in the area of Thessaloniki, Greece; c) seismic hazard disaggregation for the study site using the OpenQuake Engine [31].

shocks. Post-earthquake experimental surveys for building damage classification have also highlighted residual period elongations. For instance, a permanent frequency (or period) shift was first associated with a level of seismic damage after the 2003 Boumerdes earthquake in Algeria [23]. The damage was assessed by visual screening and was based on a redorange-green traffic light classification. The observed post-earthquake period elongation was less than $30 \%$ in the case of buildings tagged green, between 10 and $70 \%$ in the case of buildings tagged orange, and $50-70 \%$ in the case of buildings tagged red. These values were confirmed by Vidal et al. [24] after the 2011 Lorca earthquake: the period elongations were equal to $20 \%, 43 \%$, and $65 \%$ for the EMS98 damage grades 1 (no structural damage), 2 (slight structural damage, i.e., cracks in structural members), and 3-4 (moderate to very heavy structural damage, i.e., structural members with signs of inelastic deformation or failure), respectively.

This study presents an underlying probabilistic framework for the operational forecasting of time-variant damage-state probabilities for assisting decision-making in seismic emergencies. The main elements of the developed framework are operational aftershock forecasting, measurement of the fundamental period of the structure, damage accumulation and time-variant vulnerability modeling based on period elongation, and building tagging based on a traffic light scheme as a decision-making tool. A novel aspect of this study is the use of fragility curves for damage state thresholds in terms of period elongation. Period elongation is a damage proxy and can be tracked and used for damage probability forecasting. Such fragility curves should be evaluated before the mainshock, so that they can be used in decision making during an earthquake crisis. Although building modeling is used here to evaluate fragility curves, it is not used in the decision-making. First, using the epidemic type aftershock sequence model (ETAS) [25-27], synthetic sequences are generated for the given mainshock scenarios.

Subsequently, time-variant damage-state probabilities for numerical models of RC buildings are estimated based on the elongation of the period of the building models. The synthetic aftershock sequences are used in Markov chain Monte Carlo simulations [28, 29], in order to estimate the time-variant cumulative probabilities of the considered damage states during seismic sequence scenarios. The fundamental period of the structure measured at a given time can be used for two purposes. First, it can be used to determine the initial damage state of the structure, if the period was measured before the mainshock. Second, if the measurement is made during the aftershock sequence, it can be used to update the assessments for the remainder of the aftershock sequence. Finally, a red-orange-green traffic light framework is developed for classifying buildings according to performance level thresholds. The classification is done based on the increment of the time-variant cumulative probabilities of the damage states in a selected time window. In this framework, the time window considered after the mainshock depends on the time required for emergency decisions (e.g., whether to provide structural support or evacuation). The earthquake scenarios, aftershock sequences, and building models are presented in the second section of this article and are based on the test site of Thessaloniki (Greece). The third section presents the underlying probabilistic approach to the time-variant vulnerability and accumulated damage states. Finally, the traffic light framework for decision-making is presented before the conclusion.

\section{Earthquake scenarios, aftershock sequences, and building models}

\subsection{Synthetic aftershock sequences for earthquake scenarios}

For each mainshock, multiple synthetic aftershock sequences are generated in order to be used in a subsequent step to estimate the timevariant cumulative probabilities of the considered damage states. The synthetic aftershock sequences in this framework are generated using the ETAS model. This model is based on empirical laws describing the distributions of earthquakes in space, time, and magnitude. It predicts the rate of future earthquakes based on previous seismicity; it can also be used for OEF [30], and to generate synthetic catalogs. In this study, we use the ETAS model to generate two synthetic catalogs of aftershocks, as caused by two mainshock scenarios and their aftershocks.

Scenarios 1 and 2 (Fig. 1a-b) correspond to the Thessaloniki (Greece) case study: the mainshock (depth $=10 \mathrm{~km}$ ) magnitudes are 6.5 and 7.0, with epicenters located $10 \mathrm{~km}$ and $30 \mathrm{~km}$ northeast of the city, respectively. The scenarios are selected based on seismic hazard disaggregation results for Thessaloniki (Fig. 1c). The hazard disaggregation was performed using the OpenQuake Engine [31] and the computation input [32] from the 2013 Euro-Mediterranean Seismic Hazard Model (ESHM13) [33]. The ETAS model considers the uncertainty of the strike and the dip of the seismic fault. In Scenarios 1 and 2, these parameter values are sampled by the Monte Carlo simulation as random independent values from normal distributions. Sampling is performed with a standard deviation of $10^{\circ}$ and median values equal to $120^{\circ}$ and $60^{\circ}$ for strike and dip, respectively. Such fault geometries are found in the regions of the scenario epicenters $[34,35]$. In the synthetic output catalogs, earthquakes with a magnitude greater than 2.0 are simulated, but only earthquakes with magnitudes of 4.0 or more are included in the damage model. Moreover, the Guttenberg-Richter law is capped at a magnitude of 8 for the generation of synthetic earthquake sequences, as a conservative assumption compatible with the estimated maximum possible magnitude (M 7.1) for the Thessaloniki region in the last 100 years $[36,37]$.

In this study, the parameters required by the ETAS model [38] are estimated based on the earthquake catalogs from the seismological station of the Aristotle University of Thessaloniki (the 550BCE-2010 catalog $[39,40]$ and the 1995-2014 catalog [41]). A sub-catalog, which excludes earthquakes outside a $200 \mathrm{~km}$ radius around Thessaloniki, is used to consider events of similar tectonic settings. Fig. 2a gives the cumulative distribution of the magnitudes in the catalogs and sub-catalog.

The ETAS model assumes that the seismicity rate is the sum of a background rate and the rate of the aftershocks triggered by each previous event. This work is concerned with the seismicity following a large mainshock; the background rate is therefore ignored. The seismicity rate $\varphi$ at a time $t$ following an earthquake of magnitude $M$ located at a distance $r$ is given by 

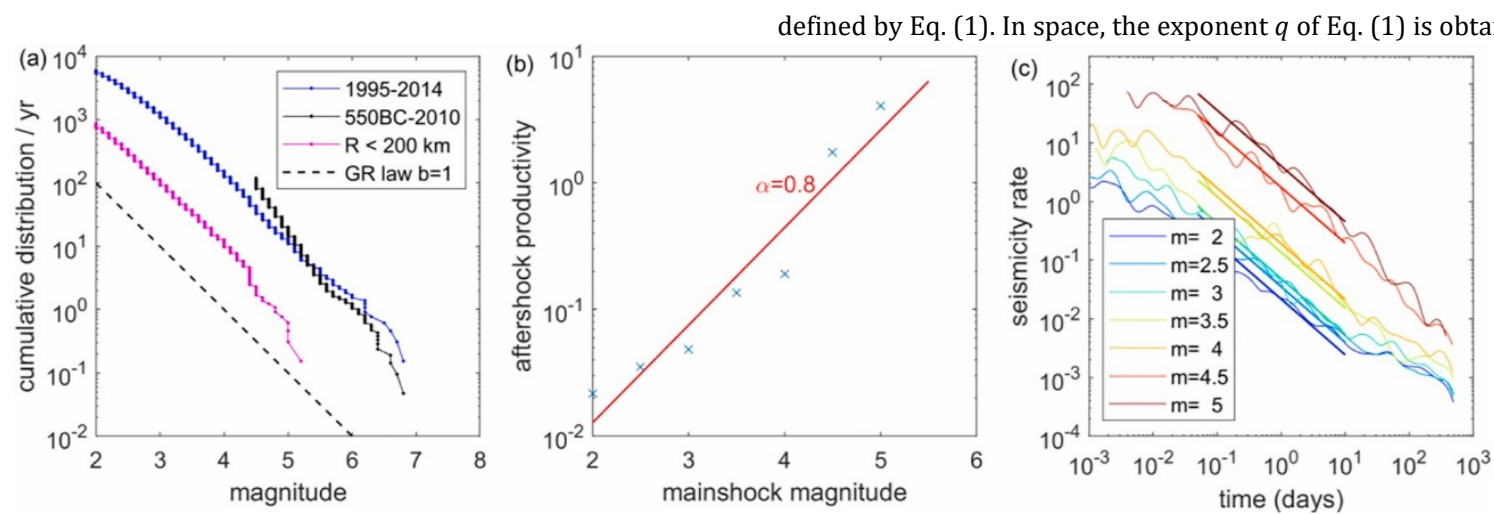

Figure 2. a) Cumulative magnitude distribution in the two historical earthquake catalogs for Greece (550 BCE-2010, 1995-2014) and in the catalog including earthquakes up to $200 \mathrm{~km}$ from Thessaloniki; b) number of aftershocks as a function of the magnitude of the triggering earthquake in the catalog of Greece (1995-2014 earthquakes with $M>2$ and distance less than $200 \mathrm{~km}$ from Thessaloniki). The solid line is a linear fit with an exponent of $\alpha=0.8 ; \mathrm{c}$ ) aftershock decay as a function of time after mainshock magnitude with 0.5 intervals (color scale). The straight lines represent Omori's law with an exponent of $p=0.95$.

$\varphi(t, r, M)=K \cdot 10^{\alpha M} \cdot \frac{1}{(t+c)^{p}} \cdot \frac{1}{(r+K(M))^{1+q}}$

here, $L(M)$ is the associated rupture length of the earthquake, and $K, c, p$, $\alpha$, and $q$ are the model parameters. The rate of aftershocks increases exponentially with the magnitude $M$ of the triggering event. In time, the seismicity rate follows Omori's law: the rate of aftershocks decreases as a power law as a function of time after the triggering event. In space, the density is constant for distances smaller than the rupture length $L(M)=$ $0.01 \cdot 10^{M / 2} \mathrm{~km}$ and decreases according to a power law at large distances $r \gg L(M)$. The magnitude distribution is usually modeled by a Gutenberg-Richter law. The total seismicity rate $R(t, r)$ is the sum of the aftershock sequences of each previous earthquake, and is given by:

$R(t, r)=\sum_{t_{i}} \varphi\left(t-t_{i},\left|\boldsymbol{r}-\boldsymbol{r}_{i}\right|, M_{i}\right)$

In the above, $\left|\boldsymbol{r}-\boldsymbol{r}_{\boldsymbol{i}}\right|$ is the norm of the vector $\boldsymbol{r}-\boldsymbol{r}_{\boldsymbol{i}}$, i.e., the 3D distance between the point corresponding to $r$ (where the seismicity rate is estimated) and the point corresponding to $\boldsymbol{r}_{\boldsymbol{i}}$ (location of earthquake $i$ ). Owing to this cascading effect, the global rate of aftershocks is much larger than the rate of direct aftershocks as modeled by Eq. (1). It also obeys Omori's law, but with a smaller $p$ exponent, and with much larger fluctuations than the rate of direct aftershocks given by Eq. (1) [42]. The cascade of secondary aftershocks also slightly modifies the spatial distribution of the aftershocks, which decays as a power law with an apparent exponent smaller than $1+q$, and induces a slow diffusion of aftershocks as a function of time [43].

The model parameters are usually estimated using a maximum likelihood method [26]. However, this method often yields biased and unrealistic values for some parameters. For example, the exponent $\alpha$ (describing the increase in aftershock productivity with the mainshock magnitude) can be underestimated if the spatial distribution of aftershocks is not isotropic [44]. In this study, we use a different approach. We start by extracting aftershocks from the catalogs, using the solution proposed by Helmstetter et al. [45]. We then estimate the model parameters of Eq. (1) ( $p=1.1, c=0.001$ day, $\alpha=0.8, K=0.008$ and $q=2.0$ ) by comparing the synthetic aftershock sequences generated by ETAS and the aftershock sequences extracted from the regional subcatalog, including events within $200 \mathrm{~km}$ from the site. Specifically, $\alpha$ is estimated by fitting the aftershock productivity as a function of the mainshock magnitude (Fig. 2b). The parameters $K, p$, and $c$ of Omori's law are found by fitting the aftershock decay as a function of the time since the mainshock (Fig. 2c). The total aftershock rate is characterized by an Omori exponent $p=0.95$, i.e., smaller than the value $p=1.1$ that characterizes the rate of direct aftershocks as lyzing the distribution of distances between the mainshock and the aftershock hypocenters. Finally, for seismic risk analysis, the duration of the simulated aftershock activity should ideally enable a return to a safe situation, i.e., after all cumulative damage to buildings. In our case, the maximum simulation time estimated by the earthquake catalog analysis is 1,000 days.

\subsection{Building models}

A series of two-dimensional low-rise and mid-rise RC building models is used (Fig. 3), and the buildings are selected as generic buildings, i.e., the focus of this study. These models are used to evaluate the fragility curves for the considered damage states, and the evaluation of the fragility curves must be made before the mainshock. The evaluated fragility curves are used in a subsequent step in order to compute the time-variant cumulative probabilities of the damage states. The models are considered representative of three-dimensional structural systems in Greece and are used to estimate losses [46]. The "HAZUS" [47] model-naming convention is used, and the model characteristics are provided in Table 1.

These models include (1) low-code and low-rise models of buildings with a structural system of bare (C1L) and regularly infilled (C3L) moment-resisting frames; (2) low- (C2L) and mid-rise (C2M) low-code models with frames coupled with shear walls; and (3) mid-rise frame models (C1M) with low, moderate, and high seismic code design. These low, moderate, and high code levels refer to seismic provisions for earthquake design. The low-code design level refers to seismic design according to the first Greek seismic code in 1959; the moderate design level refers to the supplementary clauses added in 1985; and the high-code level refers to the 2001 Greek seismic code [48]. Numerical modeling is performed with OpenSees [49], and details regarding the building modeling approach can be found in [29]. Here, the inelastic behavior of the structural elements is modeled using a distributed plasticity model of hysteretic response with stiffness degradation. The bilinear moment-curvature hysteretic models for the columns and beams are calibrated according to fiber section analysis results. In these analyses, reinforcement steel is modeled using the

Table 1

Description of the building models.

\begin{tabular}{lllll}
\hline Type & Structural system & Height & Design level & T1,orig. $(\mathrm{s})$ \\
\hline C1L & Moment resisting frames & Low-rise & Low code & 0.48 \\
C2L & Shear walls equivalent & Low-rise & Low code & 0.18 \\
C3L & Regularly infilled frames & Low-rise & Low code & 0.20 \\
C1M & Moment resisting frames & Mid-rise & Low code & 0.61 \\
C1M & Moment resisting frames & Mid-rise & Moderate code & 0.62 \\
C1M & Moment resisting frames & Mid-rise & High code & 0.64 \\
C2M & Shear walls equivalent & Mid-rise & Low code & 0.38 \\
& & & &
\end{tabular}




\section{C2L Low code}
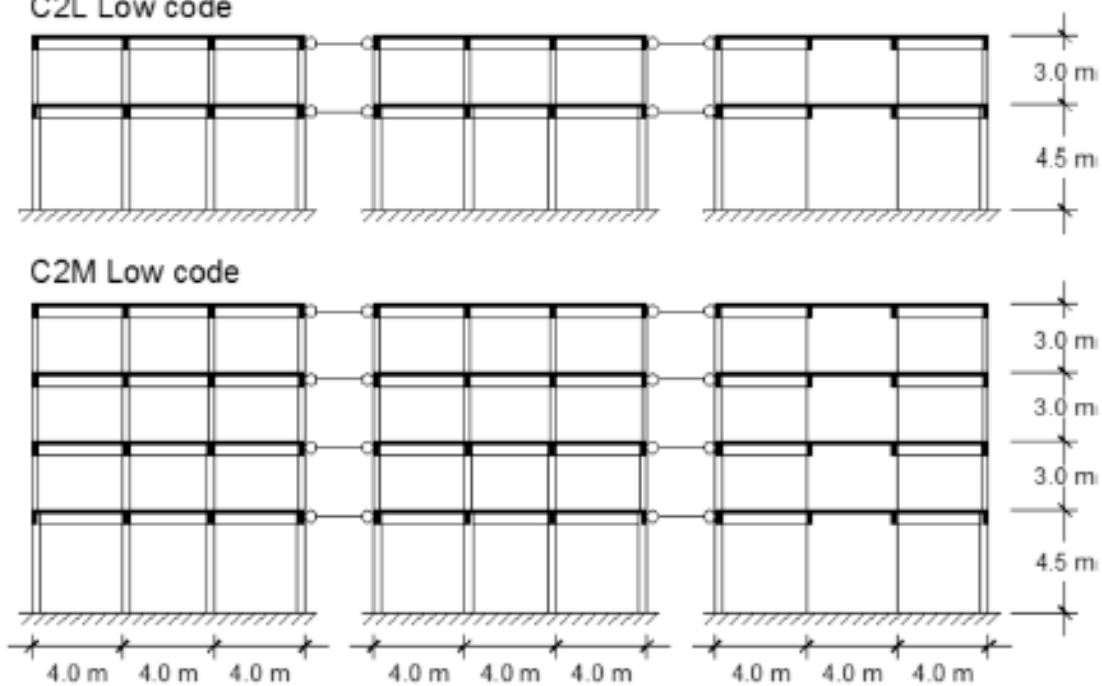

\section{C1L Low code}
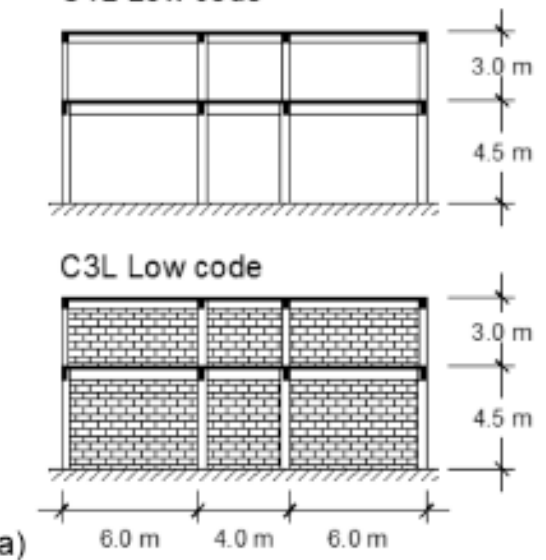

a)
C1M High/Moderate/Low Code

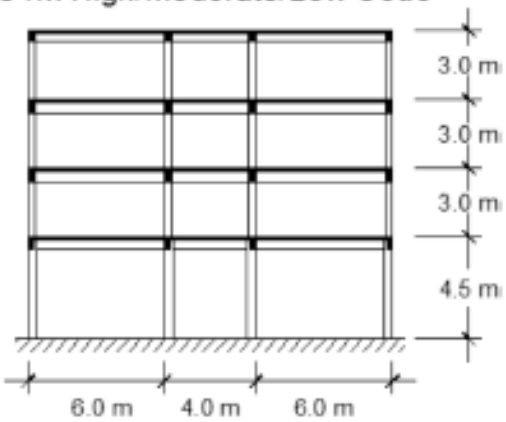

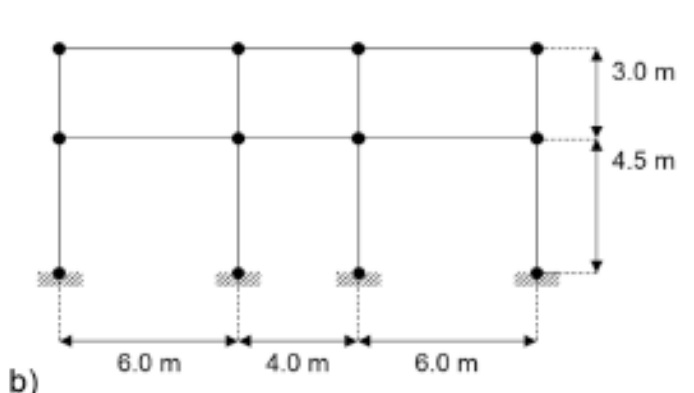

b)

Figure 3. a) 2D building models representing reinforced concrete buildings in Greece (for details, see Table 1); b) diagram of the finite element model for the C1L lowcode building.

Giuffre-Menegotto-Pinto model [50] and the Steel02 material in OpenSees. The strength degradation of confined concrete is modeled according to [51] using the material Concrete02 in OpenSees. The shear-flexural interaction in the shear walls is not modeled. In that regard, modeling the shear-flexure interaction using models such as the SFI_MVLEM element in OpenSees [52] is incompatible with the scheme herein for evaluating the fragility curves of degraded buildings in damage states. If such models were used for the shear-flexure interaction, one would have to use other procedures, such as sequential non-linear time-history analyses (e.g. [8]), to compute the fragility curves of the buildings in the damage states. Pinching in the moment-curvature loops is used only for shear walls with a factor of 0.3, assuming a strong pinching effect. The infill walls are modeled with double struts [53] with a compressive strength of 3.2 MPa and an elastic modulus of $3.2 \mathrm{GPa}$. The inelastic behavior of the struts is modeled using the Hysteretic material in OpenSees. Moreover, the p-delta effects are not simulated. According to the Greek code for interventions in existing buildings [54], the p-delta effects can be ignored if the inter-story drift sensitivity coefficient is less than a prescribed value. In the cases considered in this study, this value is not exceeded, or it is exceeded for an inter-story drift higher than 0.02 . This value of the inter-story drift corresponds to the collapse threshold for RC buildings in Greece [55]. We observe that the masonry in the $\mathrm{C} 3 \mathrm{~L}$ model leads to a considerably lower 


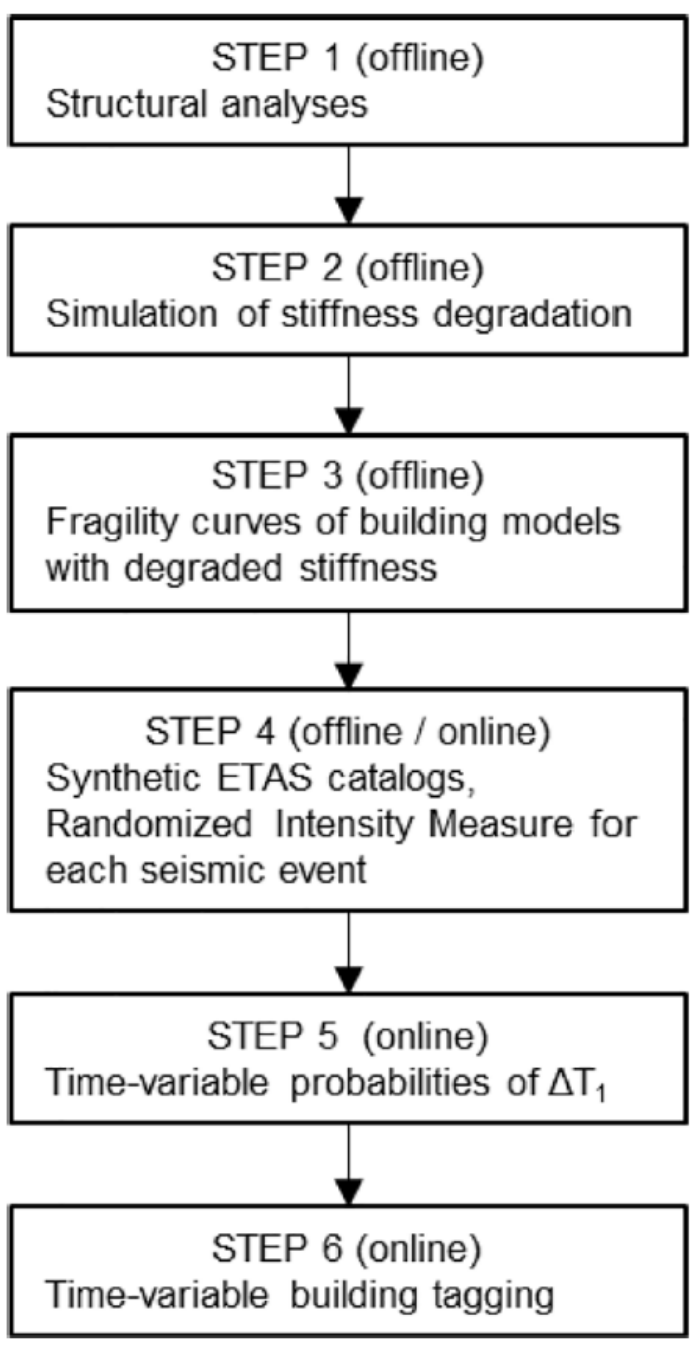

Figure 4. Flowchart of the proposed framework. Steps 1-4 are executed "offline", i.e. before the mainshock, and steps 5-6 are executed immediately after the mainshock.

first eigenperiod with respect to $\mathrm{C} 1 \mathrm{~L}$ (Table 1 ) and that the collapse mechanism of the $\mathrm{C} 3 \mathrm{~L}$ model is the same as that in the C1L model, i.e., plastic hinge formation at the bottom and top of the ground floor columns. A detailed analysis of the contribution of masonry to period elongation or structural performance is beyond the scope of this study, and readers can refer to Refs. $[6,56]$ for further information.

\section{Framework for time-variant vulnerability and cumulative dam- age state probability}

In order to estimate the probabilities of the damage states during an aftershock sequence, we consider the time-variant vulnerability of the buildings through Markov chain Monte Carlo simulations. The simulations rely on the synthetic aftershock sequences, on the fragility curves in terms of period elongation, and on measurements of the period elongation. We consider two period elongation thresholds $\left(\Delta T_{1}=40 \%\right.$ and $\Delta T_{1}$ $=60 \%$ ) as the most critical values related to the damage state, according to post-earthquake observations [23, 24]. These values represent moderate and substantial-to-very-heavy damage, respectively, and are used as performance levels for short-term decision-making in earthquake emergencies, e.g., decisions regarding immediate occupancy. At the core of the framework is the estimation of the cumulative probabilities of exceeding the period elongation thresholds at a given time $t\left(P\left[40 \%<\Delta T_{1} \leq\right.\right.$

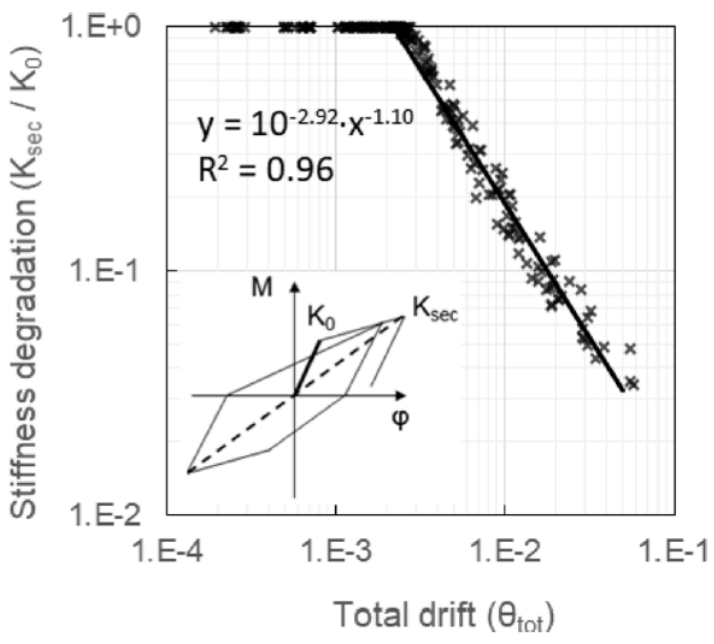

Figure 5. Example of the degradation of stiffness using the moment-curvature hysteretic loops (left insert) at the cross-section at the bottom of the outer columns of the $\mathrm{C} 1 \mathrm{M}$ low-code model for each input motion represented by crosses. The analytical equation is obtained by considering a bi-linear degradation model (continuous line) to fit the data.

$\left.60 \%](t), P\left[60 \%<\Delta T_{1}\right](t)\right)$. Based on these estimations, the time-variant probabilities of the damage states are computed as probability increments during a predefined time-window. Fig. 4 shows a flowchart of the framework developed in this study, which is summarized below.

Step 1. A probabilistic seismic demand analysis (PSDA) of the undamaged building model is performed using inelastic finite element time-history analyses. Herein, the probabilistic model is arbitrarily formulated using a ground motion bin approach [57]. Each bin consists of 15 synthetic ground motions, which are considered to be hazard-consistent, generated with SeismoArtif [58]. For each bin, a different magnitude-distance pair is considered, and the ground motions are simulated while considering a physical model (i.e, the specific barrier model) [59]. Subsequently, they are adjusted in the frequency domain so that the bin average is compatible with the median spectrum for the bin's magnitude-distance pair, as given by a ground motion prediction equation (GMPE). The GMPE is a model proposed by Ambraseys et al. [60], which has been used to assess the seismic vulnerability of RC buildings in Greece [61]. Periods in the $[0.02 \mathrm{~s}-2.0 \mathrm{~s}]$ range are selected for spectrum-adjustment, i.e., more than twice the longest eigenperiod of the models herein. Moreover, the procedure for adjusting the records leads to ground motions with reasonable variability. In particular, we consider the dispersions of the fragility curves, which reflect the variability of the selected ground motions (among other uncertainties). Specifically, the computed dispersions are similar to those reported by Kappos and Panagopoulos [62], who used the building models used herein.

Step 2. The stiffness degradation of the structural elements is modeled as a function of inter-story drift. First, the stiffness degradation ratio is defined as the ratio of the secant modulus $\left(K_{s e c}\right)$ of the momentcurvature loops resulting at each section along the length of the structural elements to the elastic stiffness $\left(K_{0}=E I\right)$ of these sections. The stiffness degradation ratio used herein is equivalent to the stiffness reduction factors for concentrated plasticity hinges $[63,64]$, which are based on the secant modulus in moment-chord rotation loops. Specifically, the hinge stiffness reduction factors are estimated as a function of inter-story drift, as normalized to the yield chord rotation [65]. Fig. 5 shows the numerical results of the stiffness degradation ratio obtained for the bottom section of an outer column on the ground floor of the C1M low-code model. Several assumptions are made: (1) similarly to $[66,67]$, power functions are computed for sections of the model's beam-column finite elements, to estimate the stiffness variations along the structural elements; (2) the location of the sections along the length of the elements is defined by the 


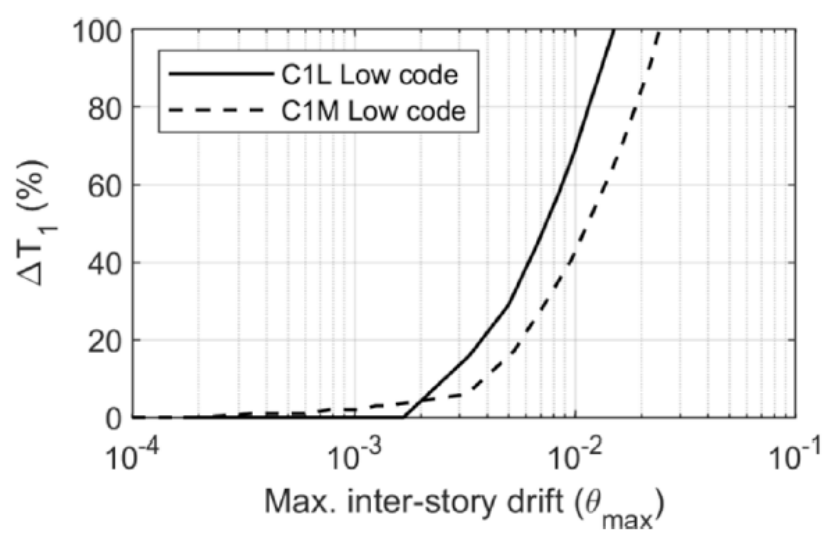

Figure 6. Period elongation $\left(\Delta T_{1}\right)$ of the building models as a function of maximum inter-story drift.
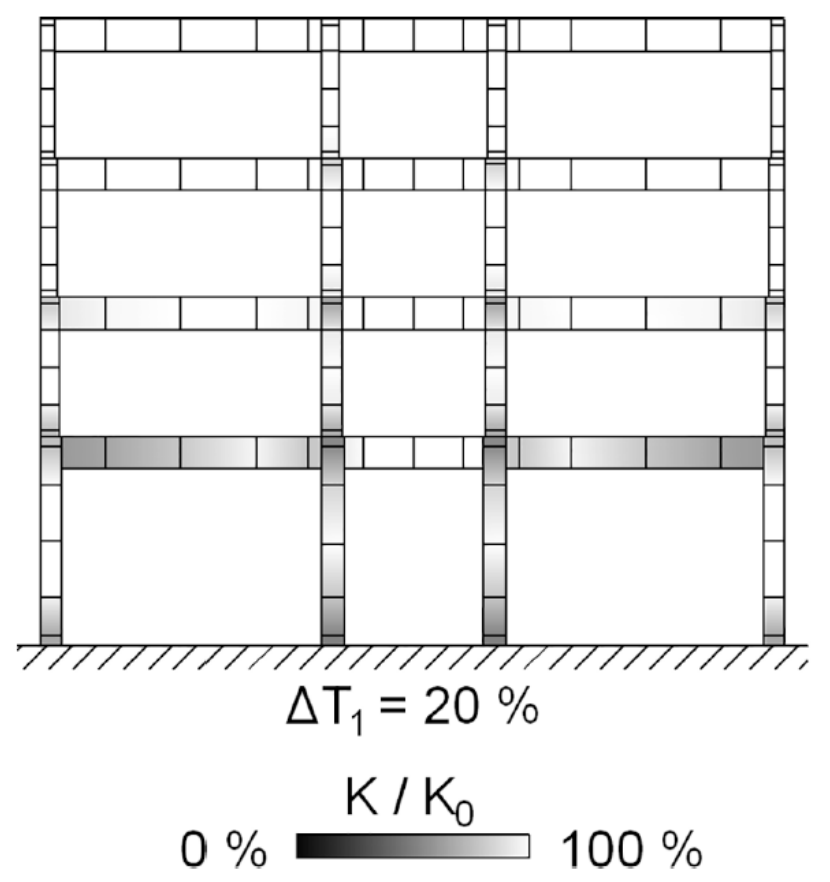

Figure 7. Example of the ratio of the stiffness of the structural elements with varying cross-section properties to the stiffness of the corresponding elements in the initial C1M low-code building model (K/K0) for $\Delta T_{1}$ equal to $20 \%$.

Gauss-Legendre quadrature rule; (3) prismatic beam elements are used to model the damaged buildings, owing to the fact that the stiffness degradation varies along the length of each element (e.g., more damage is expected to occur at the header and foot of a column than at the middle); (4) the cross-section dimensions remain constant from one section to another for each element, regardless of variations in bending stiffness; and (5) the degraded stiffness in each section is computed with analytical relationships estimated from the moment-curvature results (as given for the C1M low-code model in Fig. 5).

Finite element models of the building with increasing stiffness degradations are built using the power functions for the stiffness degradation ratio. For a given drift, the degraded stiffness values at the sections along each structural element are computed, and the corresponding model is built. One model is built for each drift in a series of drift values, e.g., from $10^{-4}$ to $5 \cdot 10^{-2}$. These models are used in modal analyses, to compute the period of each building at increasing levels of stiffness degradation. The elongation $\left(\Delta T_{1}\right)$ of the first eigenperiod of the degraded building $\left(T_{1, \text { deg. }}\right)$, relative to the period of the original building $\left(T_{1, \text { orig. }}\right)$, is computed as follows:

$\Delta T_{1}=\frac{T_{1, \text { deg. }}-T_{1, \text { orig }} .}{T_{1, \text { orig. }}}$

Fig. 6 shows $\Delta T_{1}$ with respect to the maximum inter-story drift, in the case of the $\mathrm{C} 1 \mathrm{~L}$ and $\mathrm{C} 1 \mathrm{M}$ low-code building models configured according to the procedure described. We observe that, for the same inter-story drift, the period of elongation for the four-story $\mathrm{C} 1 \mathrm{M}$ low-code model is lower than that for the two-story C1L low-code model. This makes sense based on engineering intuition, as the columns on the ground floor, where the most stiffness degradation is likely to occur, have bigger sections and additional reinforcement in the case of a four-story building. Therefore, for the same drift, we expect the columns of the four-story building to develop less damage. The maximum inter-story drift values corresponding to $\Delta T_{1}$ at $20 \%, 40 \%$, and $60 \%$ are then obtained from Fig. 6 and are used as the damage state thresholds. Here, we consider that period elongations of $20 \%, 40 \%$, and $60 \%$ correspond to the thresholds of slight, moderate, and heavy damage, respectively, based on [23, 24]. By applying the analytical relationships for the stiffness degradation at the element sections (Fig. 5), the stiffness of the element sections is computed for $\Delta T_{1}$ at $20 \%$ and $40 \%$. The buildings in the considered damage states are then modeled using the degraded stiffness values corresponding to $\Delta T_{1}$ at $20 \%$ and $40 \%$. Fig. 7 shows the degraded stiffness ratio in the case of the C1M lowcode model with $20 \%$ period elongation. For the sake of simplicity, the uncertainty in the stiffness reduction functions is not propagated analytically in the computation of $\Delta T_{1}$ as a function of the drift or in the process of estimating the stiffness of the structural elements for each damage state. However, this uncertainty and the damage state threshold uncertainty are considered by adding empirical components to the dispersion of the estimated fragility curves.

Step 3. A PSDA is performed on the degraded building models for $\Delta T_{1}$ $=20 \%$ and $40 \%$. The seismic response analyses for the PSDA for each degraded model are run successively and in a single-thread mode: on an Intel i7-4710HQ, this takes approximately $30 \mathrm{~min}$, roughly equal to the time required for every undamaged model. The fragility curves are then computed, giving the probability of each degraded building model to exceed the selected period elongation thresholds as a function of an intensity measure (IM). Although other IMs may correlate better with the structural response $[68,69]$, peak ground acceleration $(\mathrm{PGA})$ has been used in operational post-event response systems for structural evaluation [1]. Therefore, the PGA is adopted as the IM in this study. The fragility curves are evaluated with the "Cornell Method" [70, 71], i.e., by fitting a linear function of the PGA in log-scale to the inter-story drifts. As an example, Fig. 8 shows the fragility curves corresponding to the probability to exceed the threshold of moderate damage $\left(\Delta T_{1}=40 \%\right)$ for the C1M lowcode undamaged building $\left(\Delta T_{1}=0 \%\right)$, and for the building model with slight damage $\left(\Delta T_{1}=20 \%\right)$. We observe that the probability of moderate damage is higher in the case of the model which has slight damage, as expected. This is generally observed, i.e., the fragilities of the building models for any period elongation threshold increase with increasing existing period elongation.

Step 4. For each seismic event in the mainshock-aftershocks sequence, a random IM value is computed. Specifically, the IM value is a sample from a random variable with a median and standard deviation given by the GMPE for the seismic event. The fragility curves of the damaged and undamaged building models are then used to compute the elements of Markov chain transition matrices [28, 29]. By using the Markov chain, we model a building during an aftershock sequence as a system going through a chain of states, with the hypothesis that every subsequent state depends only on the current state, as follows: 


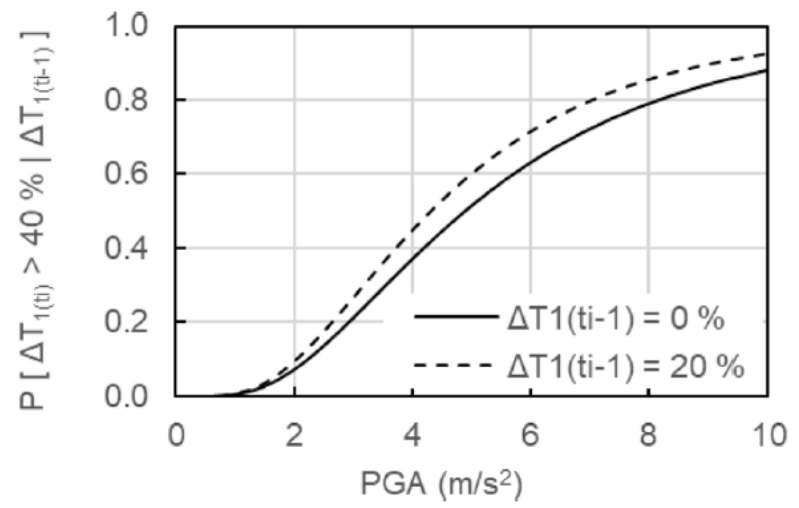

Figure 8. Examples of fragility curves for the C1M low-code model in terms of period elongation according to [26]. Probability of period elongation corresponding to $\Delta T_{1}>40 \%$ at $t_{i}$ given that $\Delta T_{1}=0 \%$ (for the undamaged building model) or $20 \%$ (for a damaged building model) at $t_{i-1}$.

$T_{(t i)}=\left[\begin{array}{cccc}P_{11}\left(t_{i}\right) & P_{12}\left(t_{i}\right) & \cdots & P_{1 m}\left(t_{i}\right) \\ 0 & P_{22}\left(t_{i}\right) & \cdots & P_{2 m}\left(t_{i}\right) \\ \cdots & \cdots & \cdots & \cdots \\ 0 & 0 & \cdots & 1\end{array}\right]$

In the above, $T_{(t i)}$ are the transition matrices, and $P$ is the probability of transition from the original state (first index) to the next state (second index). The elements in the last column are computed by:

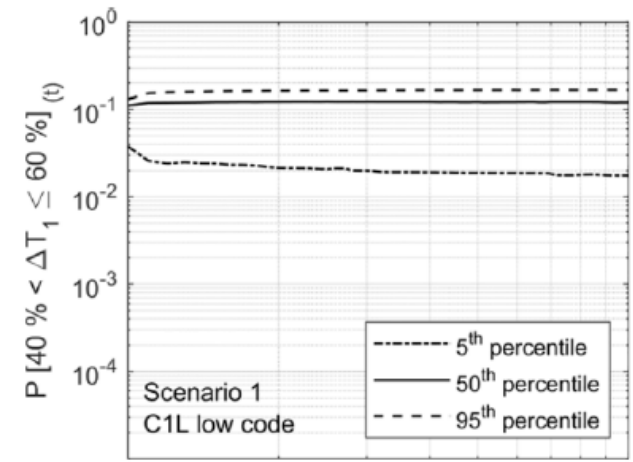

a)

$$
10^{0}
$$

t (days)

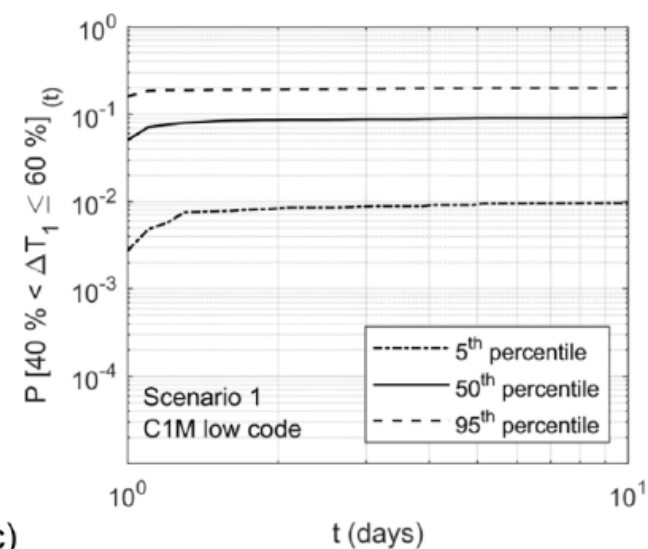

$P_{j m}\left(t_{i}\right)=P\left[D S\left(t_{i}\right)=m \mid D S\left(t_{i-1}\right)=j, I M\left(t_{i}\right)=\alpha_{i}\right]$

here, $P_{j m}\left(t_{i}\right)$ is the probability of exceeding the threshold of the highest considered damage state $(D S=m)$ at the time of a seismic event $\left(t_{i}\right)$, given that the building is in a lower damage state $(D S=j, j<m)$ at the previous time-step $\left(t_{i-1}\right)$. This value is equal to the value of the fragility curve of the building model in damage state $j$ for damage state $m$, considering the intensity measurement $\left(\alpha_{i}\right)$. In other words, $P_{j m}$ is equal to the probability of transition from damage state $j$ to damage state $m$ for a given $\alpha_{i}$. Subsequently, the elements of each matrix between the diagonal and the last column are computed by:

$$
\begin{aligned}
& P_{j k}\left(t_{i}\right) \\
& \quad=P\left[D S\left(t_{i}\right)=k \mid D S\left(t_{i-1}\right)=j, I M\left(t_{i}\right)=\alpha_{i}\right] \\
& \quad-P\left[D S\left(t_{i}\right)=k+1 \mid D S\left(t_{i-1}\right)=j, I M\left(t_{i}\right)=\alpha_{i}\right]
\end{aligned}
$$

In Eq. (6), $P_{j k}\left(t_{i}\right)$ is the probability of transition from damage state $j$ to damage state $k$, i.e., the probability of exceeding the threshold of damage state $k$ but not the threshold of state $k+1$, given that the building is in damage state $j(j<k)$. Both terms on the right-hand side of Eq. (6) are the fragilities for a given intensity measurement $\left(\alpha_{i}\right)$, i.e., equal to the value of the fragility curves of the building model in damage state $\mathrm{j}$ for damage states $k$ and $k+1$, respectively. Finally, the diagonal elements are computed by:
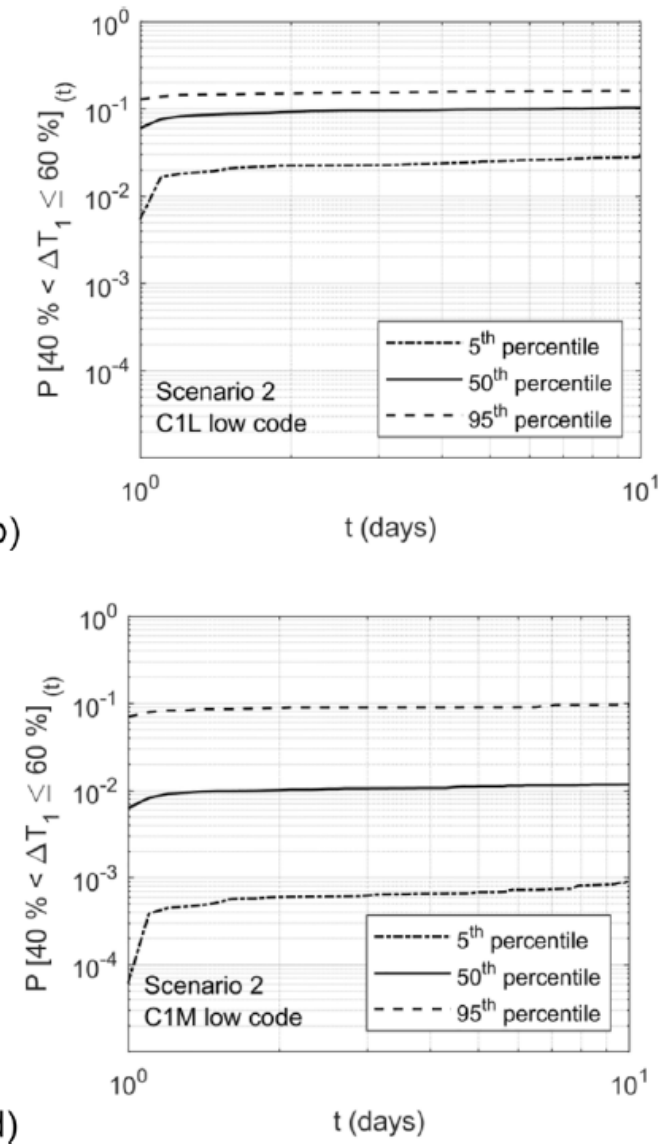

Figure 9. Examples of cumulative probability of period elongation corresponding to $40 \%<\Delta T_{1} \leq 60 \%$ after the time of the mainshock ( $t=1$ ) during synthetic aftershock sequences in the case of the C1L low-code model in a) Scenario 1 and b) Scenario 2, and the C1M low-code model in c) Scenario 1 and d) Scenario 2. 
Table 2

Ratio of the 50th percentile of the cumulative probability of period elongation $60 \%\left(P\left[60 \%<\Delta T_{1}\right](t)\right)$ at the end of the aftershock sequences to the 50 th percentile of $P\left[60 \%<\Delta T_{1}\right]$ owing to the mainshock in Scenarios 1 and 2.

\begin{tabular}{|c|c|c|c|c|c|c|c|}
\hline \multirow[t]{3}{*}{ Type } & \multirow[t]{3}{*}{ Design level } & \multicolumn{6}{|c|}{ Scenario 1} \\
\hline & & \multicolumn{2}{|c|}{ 50 $0^{\text {th }}$ percentile of $P\left[60 \%<\Delta T_{1}\right](t)$} & \multirow[t]{2}{*}{ Ratio } & \multicolumn{2}{|c|}{ 50 $0^{\text {th }}$ percentile of $P\left[60 \%<\Delta T_{1}\right](t)$} & \multirow[t]{2}{*}{ Ratio } \\
\hline & & $t_{\text {main }}$ & $t_{\text {end }}$ & & $t_{\text {main }}$ & $t_{\text {end }}$ & \\
\hline C1L & Low code & 0.3582 & 0.6912 & 1.93 & 0.0854 & 0.1796 & 2.10 \\
\hline $\mathrm{C} 2 \mathrm{~L}$ & Low code & 0.3002 & 0.5751 & 1.92 & 0.0836 & 0.1754 & 2.10 \\
\hline $\mathrm{C} 3 \mathrm{~L}$ & Low code & 0.0356 & 0.0954 & 2.68 & 0.0034 & 0.0076 & 2.21 \\
\hline C1M & Low code & 0.0384 & 0.1059 & 2.76 & 0.0028 & 0.0064 & 2.26 \\
\hline $\mathrm{C} 1 \mathrm{M}$ & Moderate code & 0.0250 & 0.0748 & 2.99 & 0.0015 & 0.0034 & 2.29 \\
\hline $\mathrm{C} 1 \mathrm{M}$ & High code & 0.1367 & 0.3226 & 2.36 & 0.0173 & 0.0377 & 2.18 \\
\hline $\mathrm{C} 2 \mathrm{M}$ & Low code & 0.0152 & 0.0520 & 3.41 & 0.0011 & 0.0026 & 2.34 \\
\hline
\end{tabular}

$P_{j j}\left(t_{i}\right)=1-1\left[D S\left(t_{i}\right)=j+1 \mid D S\left(t_{i-1}\right)=j, I M\left(t_{i}\right)=\alpha_{i}\right]$,

$i=\{1, \ldots, n\}, j=\{1, \ldots, m\}$

here, $P_{j j}\left(t_{i}\right)$ is the probability of remaining in damage state $j$ and not exceeding the threshold of damage state $j+1$ for a given intensity measurement $\left(\alpha_{i}\right)$, given that the building is in state $j$. As with Eq. (6), the second term of the right-hand side corresponds to the fragility. The elements below the diagonal of the transition matrices are assumed to be equal to zero, i.e., it is assumed that transitions to lower damage states are impossible. In other words, it is assumed that once the structural period has been elongated, its reduction is impossible.

One transition matrix is computed for each seismic event of the mainshock-aftershock sequence, and one series of matrices is computed for each building model. As the value of the $I M$ is different for each event, the Markov chain is time-inhomogeneous, i.e., the values of the elements of the transition matrix are time-dependent. The probabilities of the damage states at the times of the seismic events are computed with a Markov chain with discrete time and space elements, as follows:

$\left[P\left[D S\left(t_{n}\right)=1\right] \ldots P\left[D S\left(t_{n}\right)=j\right] \ldots P\left[D S\left(t_{n}\right)=m\right]\right]=$

$\left[\begin{array}{llll}1 & 0 & \ldots & 0\end{array}\right] \prod_{1}^{n} T\left(t_{i}\right), i=\{1, \ldots, n\}, j=\{1, \ldots, m\}$

In our case studies, zero values are assigned to all $m$ elements of the initial vector, which is on the right-hand side of Eq. (8), except for the first element of the vector, which is equal to 1 . It is thus assumed that the building is undamaged before the mainshock. In a real application, it would be possible to define the initial vector based on measurements of the fundamental period of the building, i.e., considering the actual structural health. Moreover, it would be possible to update the assessments at a given time during the aftershock sequence. To do so, in addition to using the measured fundamental period to define the initial vector, the transition matrices for the aftershocks after the given time should be used.

Step 5. The probabilities of the damage states computed with Eq. (8) are computed at the times of the seismic events. Therefore, their timestep is variable, and depends on the time of the earthquakes within a sequence. Furthermore, the number and times of the seismic events in each synthetic catalog vary according to the ETAS algorithm. The computed probabilities are re-sampled with a constant time-step of 0.1 day. This is performed to compute the percentiles of the probability of each damage

Table 3

Comparative risk ranking of the building models in Scenarios 1 and 2 .

\begin{tabular}{llll}
\hline Type & Design level & Rank & \\
\cline { 3 - 4 } & & Scenario 1 & Scenario 2 \\
\hline C1L & Low code & 1 & 1 \\
C2L & Low code & 2 & 2 \\
C3L & Low code & 5 & 4 \\
C1M & Low code & 4 & 5 \\
C1M & Moderate code & 6 & 6 \\
C1M & High code & 3 & 3 \\
C2M & Low code & 7 & 7 \\
\hline
\end{tabular}

state as a function of time. Figs. 9 and 10 show the 5th, 50th, and 95th percentiles of the computed probabilities $P\left[40 \%<\Delta T_{1} \leq 60 \%\right](t)$ and $P\left[60 \%<\Delta T_{1}\right](t)$ in scenarios 1 and 2 , respectively, for the C1L and $\mathrm{C} 1 \mathrm{M}$ low-code models. The time of the mainshock is $t=1.0$ day. As expected, the highest accumulation of $P\left[\Delta T_{1}>60 \%\right]$ is during the first day, given that the seismicity rate decreases constantly with time (Fig. 2).

Step 6. The final step of the procedure is described in Section 4.

The slopes of the curves in Figs. 9 and 10 depend on the rate of aftershocks and the rate at which the probability of period elongation is accumulated in each Monte Carlo simulation. The increasing trends of $P[60 \%$ $\left.<\Delta T_{1}\right](t)$ (Figs. 9 and 10) are explained by the fact that the buildings may accumulate damage during the aftershock sequence. In addition, the curves become gradually horizontal over the course of time. This is because the rate of aftershocks reduces with time.

There are cases where $P\left[60 \%<\Delta T_{1}\right](t)$ is higher than $P\left[40 \%<\Delta T_{1}\right.$ $\leq 60 \%](t)$ (e.g., in the case of the C1M low-code model), i.e., the probability of extensive damage is higher than the probability of moderate damage. Moreover, there are cases in which the probability of damage states corresponding to light or moderate damage may decrease over time. Such cases include the $P\left[40 \%<\Delta T_{1} \leq 60 \%\right](t)$ result for the C1L low-code mode in Scenario 1 (Fig. 9a). Such results may appear confusing, but they are coherent with the fact that damage states are mutually exclusive, i.e., a high probability of one damage state is accompanied by lower probabilities of the other damage states.

The cumulative probability of exceeding $\Delta T_{1}=60 \%$ also provides information on the probability of observing the damage level (based on the period elongation threshold) at a given time after the mainshock, as compared with the damage expected owing to the mainshock alone. The ratio of the $50^{\text {th }}$ percentile of $P\left[60 \%<\Delta T_{1}\right](t)$ at the end of the scenarios, divided by the value of the $50^{\text {th }}$ percentile owing to the mainshock, is provided in Table 2. This ratio varies according to building model, from 1.92 to 3.41 and from 2.10 to 2.34 in Scenarios 1 and 2, respectively. For both scenarios, this suggests that the aftershock sequence contributes significantly to the probabilities of the final damage states.

Moreover, the computation of $P\left[60 \%<\Delta T_{1}\right](t)$ allows for the assessment of the comparative seismic risk of the building models in the selected scenarios. In the context of an operational framework for postearthquake risk management, such rankings are intended to help decision-makers prioritize actions for building classes. The building models are ranked in Table 3 according to their $P\left[60 \%<\Delta T_{1}\right](t)$ results at the ends of Scenarios 1 and 2. A higher rank corresponds to a higher risk relative to the other building models. In both scenarios, the low-rise bare moment-resisting frame model (C1L) and the mid-rise shear wall model (C2M) are at the top and bottom of the ranking, respectively. The only difference between the scenarios is the position of the low-code C3L and C1M models, which switch between the $4^{\text {th }}$ and $5^{\text {th }}$ ranks.

Interestingly, in Table 3, the C1M high-code model has a worse rank than the C1M low-code model. Both models are mid-rise models with bare frames; their only difference is the code under which they were designed. The high-code model has a worse performance according to this ranking. However, this should not lead to the conclusion that it is less safe. This 


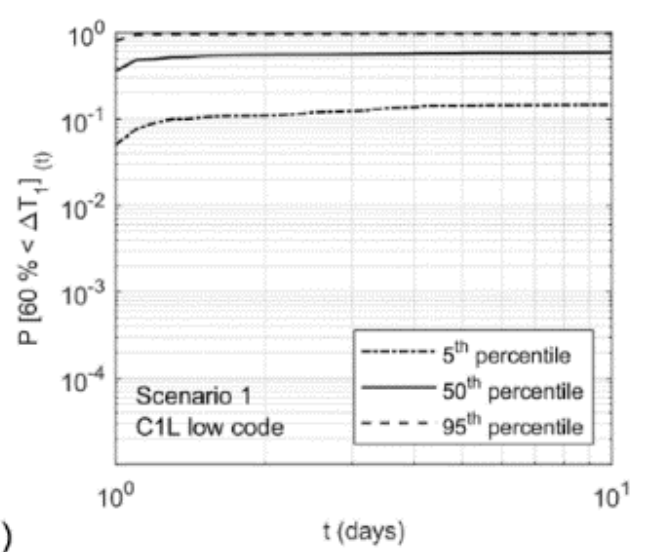

a)

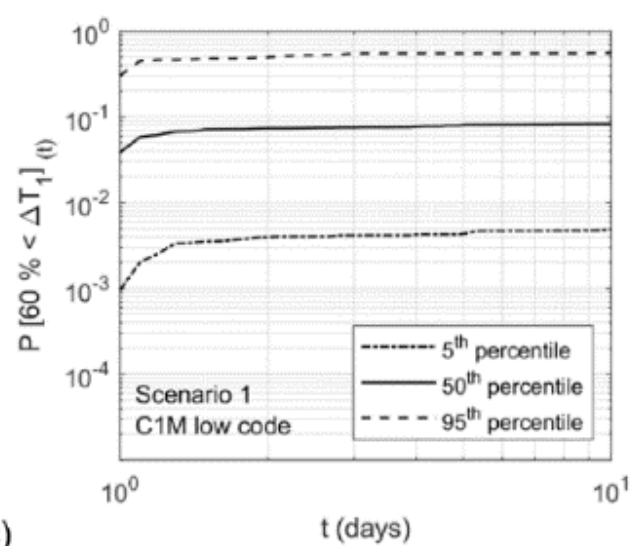

c)

t (days)
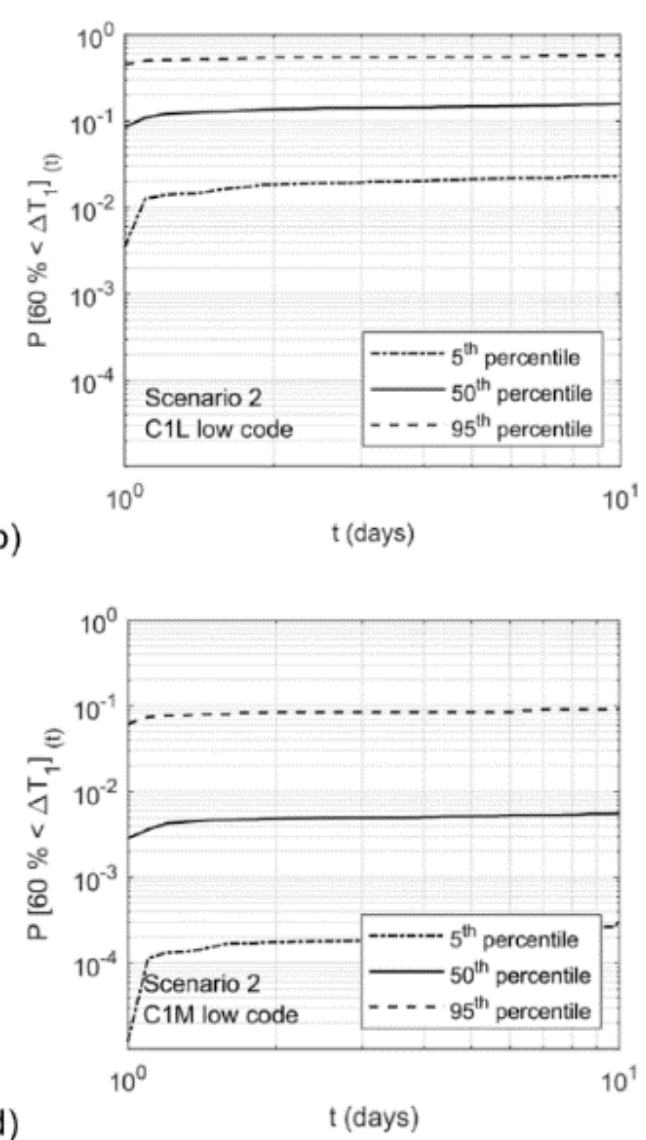

d)

Figure 10. Examples of cumulative probability of period elongation corresponding to $60 \%<\Delta T_{1}$ after the time of the mainshock ( $\left.t=1\right)$ during synthetic aftershock sequences in the case of the C1L low-code model in a) Scenario 1 and b) Scenario 2, and the C1M low-code model in c) Scenario 1 and d) Scenario 2.

result may be explained by the differences between the philosophies of modern and old codes. In Greece and other countries, a behavior factor is used in building design with recent codes. This behavior factor leads to reduced design spectra with respect to the elastic code spectra. This implies that, under the design loads, the buildings will most likely have an inelastic response. In the old code, an inelastic response was undesirable, and the design relied on strength. As an example, it is noted that the yield moment at the foot of the outer columns of the high-code model is approximately $2 / 3$ of the yield moment at the same section in the low-code model. Recent codes aim to prevent collapse under the design loads by designing structural members with sufficient ductility to develop damage and thus absorb energy, thereby avoiding brittle collapse mechanisms. More ductility means more stiffness degradation and a higher period elongation before collapse. Therefore, the same amount of period elongation appears to correspond to different levels of damage in old and modern code buildings. In that respect, the ranking in Table 3 may be misleading with respect to the high-code model. A better ranking would be possible if the damage state thresholds were calibrated to reflect the same level of damage across all models. However, this is out of the scope of this article, and further investigation is required in this direction.

\section{Time-variant damage state probability and traffic light concept for decision-making}

The so-called "traffic light" model is often used for decision-making. It evaluates the safety of structures according to criteria related to their operability and occupancy, assigning each building to one of three categories: the tolerable zone (green), the intermediate zone (orange), and the intolerable zone (red). This strategy has already been applied for post-earthquake crisis management, which consists in visually inspecting buildings and classifying them according to occupancy safety based on an empirical expert appraisal $[23,24]$. It has also been used for continuous and online condition-based solutions for structural aging [72]. Typically, the "traffic light" defines a "green" level as indicating that the buildings are safe, have no apparent damage, and can be occupied again, an "orange" level as indicating that the buildings present all of the characteristics of damaged buildings, but with a high level of uncertainty, and a "red" level as indicating that occupancy should be suspended immediately and the building demolished. Previous studies $[23,24]$ have shown the benefits of experiment-based assessment of the fundamental period of structures in reducing classification uncertainties, particularly for the "orange" level.

In our study, a period elongation-based red/orange/green "traffic light" scheme is proposed to classify buildings according to the estimated time-variant probabilities of damage states. A probability increment between $t$ and $t+7$ days $[1,7]\left(P\left[40 \%<\Delta T_{1} \leq 60 \%\right](t, t+7), P[60 \%<\right.$ $\left.\left.\Delta T_{1}\right](t, t+7)\right)$ is used to tag buildings, based on tolerable damage state probabilities. The $5^{\text {th }}, 50^{\text {th }}$, and $95^{\text {th }}$ percentiles of the computed probability are considered for four tolerable annual rates $\left(\lambda_{t o l}\right)$ of damage state probabilities (Table 4), based on the performance levels selected for seismic risk analysis. Silva et al. [73] proposes $5 \cdot 10^{-5}$ and $10^{-4}$ as tolerable annual rates of collapse leading to loss of human life for low and moderate earthquake-prone countries, such as Greece $\left(10^{-4}\right)$. These values are adopted herein $\left(\lambda_{t o l .1}\right.$ and $\left.\lambda_{t o l .2}\right)$ for low and moderate seismicity regions, respectively, as "human life safety" performance levels.

The thresholds $\lambda_{\text {tol.3 }}$ and $\lambda_{\text {tol.4 }}$ correspond to the thresholds of the probabilities of structural failure for normal buildings and buildings that 
Table 4

Tolerable risk thresholds used in the building tagging framework.

\begin{tabular}{llll}
\hline Threshold & Tolerable annual rate & Tolerable $P(T=475 \mathrm{y})$ & Element at risk \\
\hline 1 & $\lambda_{\text {tol. }}=1 \cdot 10^{-4}$ & $4.6 \cdot 10^{-2}$ & Structure and human life (moderate seismicity region) \\
2 & $\lambda_{\text {tol.2 }}=5 \cdot 10^{-5}$ & $2.4 \cdot 10^{-2}$ & Structure and human life (low seismicity region) \\
3 & $\lambda_{\text {tol. } 3}=10^{-6}$ & $4.7 \cdot 10^{-4}$ & Normal structure (failure with moderate damage) \\
4 & $\lambda_{\text {tol. } 3}=10^{-7}$ & $4.7 \cdot 10^{-5}$ & Critical structure (failure with moderate damage) \\
\hline
\end{tabular}

are part of critical infrastructure, respectively. Herein, these thresholds correspond to the Eurocode 0 [74] reliability classes RC2 and RC3. EC0 does not specify tolerable rates of structural failure and exceedance probabilities, but it does indicate an annual probability of failure, as follows:

$P(T=1 y)=\Phi(-\beta)$

In the above, $\Phi$ is a cumulative distribution function of the standard normal distribution (mean $\mu=0$ and standard deviation $\sigma=1$ ). The EC0 recommended minimum values of the reliability index $(\beta)$ for the RC2 and RC3 structures are 4.7 and 5.2, respectively. Using Eq. (9), the tolerable annual rates of failure $\left(\lambda_{f o l, 3}\right.$ and $\left.\lambda_{f o l, 4}\right)$ are computed as equal to $10^{-6}$ and $10^{-7}$, respectively. Finally, the four thresholds of tolerable risk, according to the standard values for earthquake design and performancebased assessment, are computed using a Poisson model as follows:

$P(T)=1-e^{-\lambda T}$

here, $\lambda=\lambda_{\text {tol }}$, and a time window $T$ of 475 years is arbitrarily assumed.
This arbitrary selection is similar to the arbitrary selection of a tolerable level for the probability of collapse in 7 days in [7].

In the context of the proposed tagging scheme, tags are given based on the levels of the probability of damage states, with respect to tolerable probability thresholds. If there were no uncertainties in the estimated damage state probabilities, one would simply compare the probability of a damage state with its tolerable threshold. If the probability of the damage state were higher than the tolerable threshold, then the red tag would be assigned. Otherwise, the green would be assigned. However, given the uncertainty in the estimated damage-state probabilities, tagging is considered possible after defining a level of confidence. Here, we arbitrarily select a $95 \%$ level of confidence. Therefore, when the $5^{\text {th }}$ percentile of the probability of a damage state is higher than its tolerable threshold, the red tag is assigned. The green tag is assigned when the $95 \%$ percentile of the probability of a damage state is lower than its tolerable threshold. This leads to a period between the red and green tag periods, during which neither the red nor the green tag can be assigned according to this scheme. Throughout the period between the red and green tag periods,

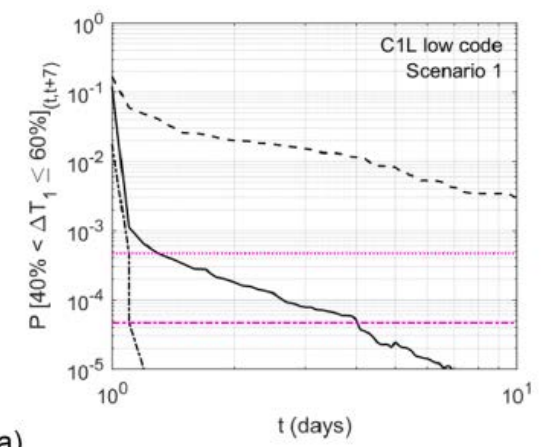

a)

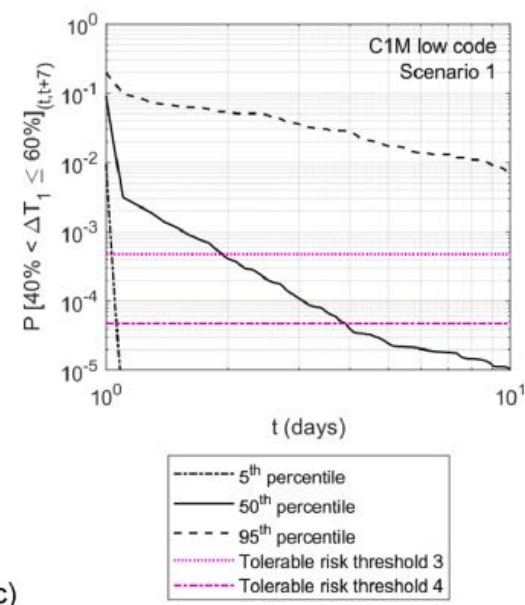

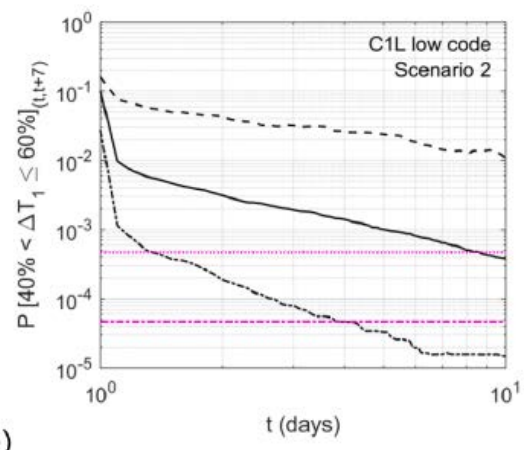

b)

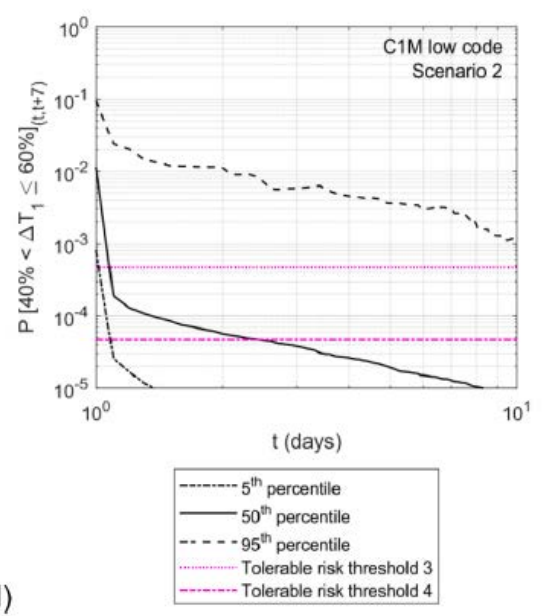

Figure 11. Examples of probability of period elongation corresponding to $40 \%<\Delta T_{1} \leq 60 \%$ between $\mathrm{t}$ and $t+7$ days during synthetic aftershock sequences in the case of the C1L low-code model in a) Scenario 1 and b) Scenario 2 and the C1M low-code model in c) Scenario 1 and d) Scenario 2. 


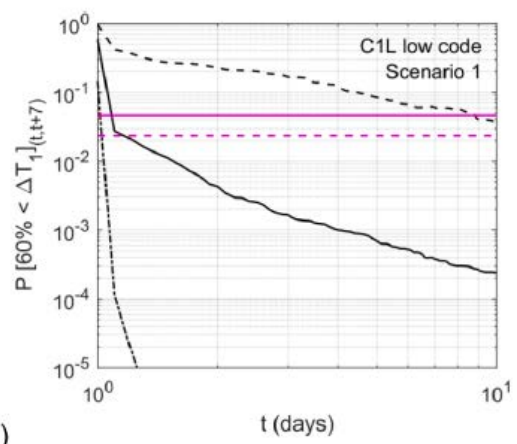

a)

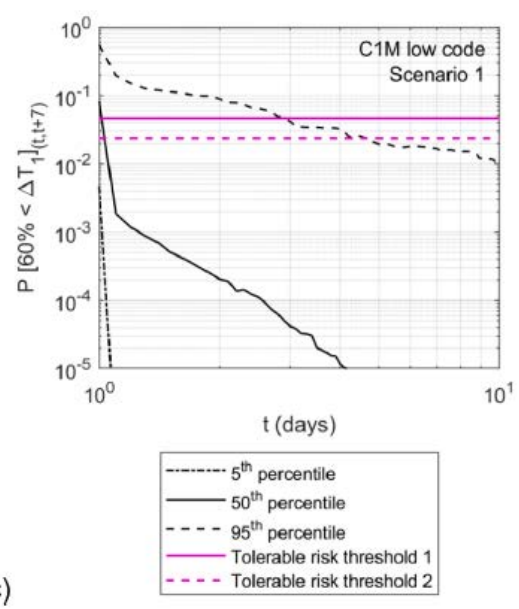

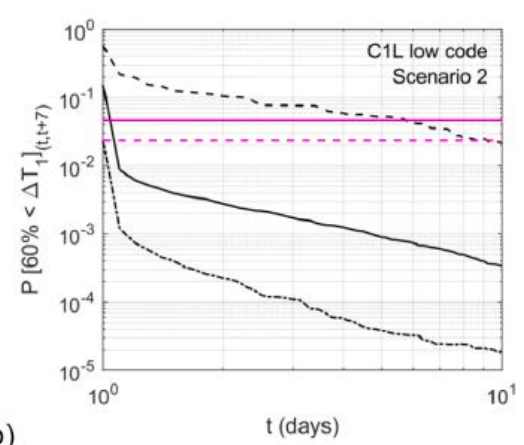

b)

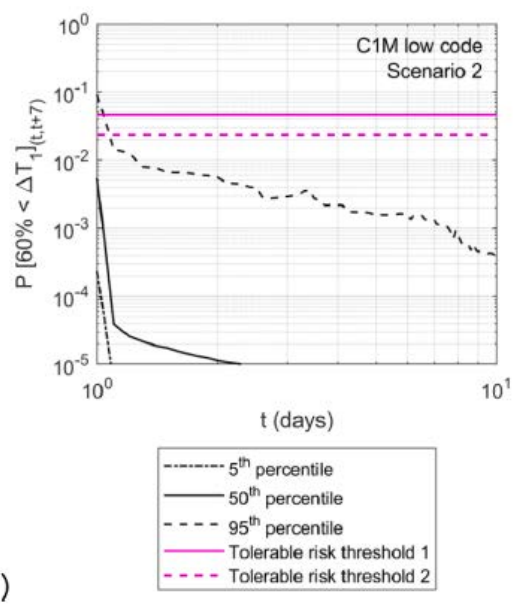

Figure 12. Examples of probability of period elongation corresponding to $60 \%<\Delta T_{1}$ between $\mathrm{t}$ and $t+7$ days during synthetic aftershock sequences in the case of the C1L low-code model in a) Scenario 1 and b) Scenario 2 and the C2L low-code model in c) Scenario 1 and d) Scenario 2.

the orange tag is assigned, as proposed in [1]. The orange tag marks a period during which we cannot say if the probability of the damage state is higher or lower than its tolerable threshold, based on the defined level of confidence.

At this point, it is worth elaborating on the tagging scheme. A red tag based on $\lambda_{t o l 1}$ and $P\left[60 \%<\Delta T_{1}\right](t, t+7)$ signifies that the accumulated probability of human life loss owing to extensive structural damage between $t$ and $t+7$ days is intolerable. This assumption is justified if we consider that $P\left[60 \%<\Delta T_{1}\right](t, t+7)$ corresponds to the accumulated probability of period elongation corresponding to extensive damage between $t$ and $t+7$ days, and that the level of this probability exceeds, with $95 \%$ confidence, the corresponding tolerable threshold. Similarly, a red tag based on $\lambda_{\text {tol4 }}$ and $P\left[40 \%<\Delta T_{1} \leq 60 \%\right](t, t+7)$ means that the accumulated probability of moderate structural damage between $t$ and $t+$ 7 days is intolerable. In general, all building models are tagged green, regardless of the tolerable damage-state probability thresholds, once a certain amount of time has elapsed since the mainshock; this time depends on the building model and the scenario. This happens because the rate of aftershocks reduces with time, and the accumulation of the probability of damage practically stops at some point.

Current building tagging procedures typically give a tag which remains unchanged. In the procedure herein, a tag may change from red to orange to green. It should be noted that current tagging operations are made with respect to safety during future earthquakes. The proposed tagging procedure assigns tags are based on the tolerable damage state probabilities and the accumulated damage state probability in 7 days. The selection of a 7-day interval is arbitrary, and was adopted by Iervolino et al. (2014) [7], where the accumulated probability of failure in 7 days was computed. This interval can be tuned according to the decision-making context. For example, if decisions should be made based on the cumulative earthquake risk over 3 days, then a 3-day interval should be used. The 7-day interval means that tags are assigned with respect to the safety during a 7-day window during the ongoing aftershock sequence. This also means that even buildings tagged red after the mainshock according to

Table 5.

Estimated time in days after the mainshock until the red $\left(t_{\text {red }}\right)$ and orange $\left(t_{\text {orange }}\right)$ tag periods end in Scenario $1(M 6.5, R 10 \mathrm{~km})$, according to the four tolerable risk thresholds considered in this study (see Table 4).

\begin{tabular}{|c|c|c|c|c|c|c|c|c|c|}
\hline \multicolumn{2}{|c|}{ Tolerable risk threshold } & \multicolumn{2}{|l|}{ (1) } & \multicolumn{2}{|l|}{$(2)$} & \multicolumn{2}{|l|}{ (3) } & \multicolumn{2}{|l|}{ (4) } \\
\hline Building type & Seismic design level & $t_{\text {red }}$ (days) & $t_{\text {orange }}$ (days) & $t_{\text {red }}$ (days) & $t_{\text {orange }}$ (days) & $t_{\text {red }}$ (days) & $t_{\text {orange }}$ (days) & $t_{\text {red }}$ (days) & $t_{\text {orange }}$ (days) \\
\hline $\mathrm{C} 1 \mathrm{~L}$ & low code & 0.1 & 7.9 & 0.1 & 17.5 & 0.1 & 54.8 & 0.1 & 210.2 \\
\hline $\mathrm{C} 2 \mathrm{~L}$ & low code & 0.1 & 7.7 & 0.1 & 16.0 & 0.1 & 121.0 & 0.1 & 404.5 \\
\hline C3L & low code & 0.0 & 1.9 & 0.0 & 3.7 & 0.1 & 210.2 & 0.1 & 533.3 \\
\hline C1M & low code & 0.0 & 2.0 & 0.0 & 3.7 & 0.1 & 216.4 & 0.1 & 516.4 \\
\hline $\mathrm{C} 1 \mathrm{M}$ & moderate code & 0.0 & 1.7 & 0.0 & 3.2 & 0.1 & 210.9 & 0.1 & 442.4 \\
\hline C1M & high code & 0.0 & 4.6 & 0.1 & 12.8 & 0.1 & 171.4 & 0.1 & 406.0 \\
\hline $\mathrm{C} 2 \mathrm{M}$ & low code & 0.0 & 1.7 & 0.0 & 3.1 & 0.1 & 215.6 & 0.1 & 535.0 \\
\hline
\end{tabular}


Table 6.

Estimated time in days after the mainshock until the red $\left(t_{\text {red }}\right)$ and orange ( $\left.t_{\text {orange }}\right)$ tag periods end in Scenario $2(M 7.0, R 30 \mathrm{~km})$, according to the four tolerable risk thresholds considered in this study (see Table 4).

\begin{tabular}{|c|c|c|c|c|c|c|c|c|c|}
\hline \multicolumn{2}{|c|}{ Tolerable risk threshold } & \multicolumn{2}{|l|}{ (1) } & \multicolumn{2}{|l|}{ (2) } & \multicolumn{2}{|l|}{ (3) } & \multicolumn{2}{|l|}{ (4) } \\
\hline Building type & Seismic design level & $t_{\text {red }}$ (days) & $t_{\text {orange }}$ (days) & $t_{\text {red }}$ (days) & $t_{\text {orange }}$ (days) & $t_{\text {red }}$ (days) & $t_{\text {orange }}$ (days) & $t_{\text {red }}$ (days) & $t_{\text {orange }}$ (days) \\
\hline C1L & low code & 0.0 & 4.8 & 0.0 & 8.2 & 0.4 & 204.3 & 2.9 & 674.1 \\
\hline $\mathrm{C} 2 \mathrm{~L}$ & low code & 0.0 & 4.3 & 0.1 & 8.2 & 0.8 & 193.2 & 4.4 & 675.6 \\
\hline C3L & low code & 0.0 & 0.1 & 0.0 & 0.1 & 0.1 & 19.3 & 0.1 & 136.5 \\
\hline C1M & low code & 0.0 & 0.1 & 0.0 & 0.1 & 0.1 & 19.9 & 0.1 & 136.5 \\
\hline $\mathrm{C} 1 \mathrm{M}$ & moderate code & 0.0 & 0.1 & 0.0 & 0.1 & 0.0 & 13.0 & 0.1 & 73.8 \\
\hline $\mathrm{C} 1 \mathrm{M}$ & high code & 0.0 & 0.3 & 0.0 & 1.5 & 0.1 & 72.9 & 0.8 & 443.2 \\
\hline $\mathrm{C} 2 \mathrm{M}$ & low code & 0.0 & 0.0 & 0.0 & 0.1 & 0.1 & 14.4 & 0.1 & 99.2 \\
\hline
\end{tabular}

the proposed tagging procedure will eventually be tagged green, when the rate of aftershocks drops to a level at which practically no damage state probability is accumulated. Moreover, a tag from the proposed procedure can coexist with a tag from current building tagging operations. For example, a severely damaged building would be tagged red by current building tagging operations. The same building would be tagged green by the proposed tagging procedure at the end of the aftershock sequence.

Figs. 11 and 12 show the results of the operational damage state probability forecasting for different building classes and different performance levels. As $\lambda_{\text {tol1 }}$ and $\lambda_{\text {tol } 2}$ refer to life safety and $\lambda_{t o l 3}$ and $\lambda_{t o l 4}$ refer to the probability of observing any structural failure, $\lambda_{\text {tol } 1}$ and $\lambda_{\text {tol } 2}$ are represented for $P\left[60 \%<\Delta T_{1}\right](t, t+7)$, and $\lambda_{\text {tol3 }}$ and $\lambda_{\text {tol4 }}$ are represented for $P\left[40 \%<\Delta T_{1} \leq 60 \%\right](t, t+7)$. The time-variant probabilities of the damage states depend on the scenarios and building models. As expected, the highest probability of the two damage states is observed at the time of the mainshock. Subsequently, a rapid decrease of the $5^{\text {th }}, 50^{\text {th }}$, and $95^{\text {th }}$ percentiles of the computed probability is observed on the first day after the mainshock, followed by a period of slower decrease. The end of the risk period corresponds to the moment when the percentiles of the computed probability drop to very small values (e.g., less than $10^{-5}$ ). The computed duration of this period is also highly variable, and depends on the building typology and the tolerable annual rate of damage state thresholds $\lambda_{\text {tol }}$. With these figures, decisions can be made based on the structure's health as estimated on the basis of the period elongation, as measured using experimental data.

Fig. 11 shows the computed $P\left[40 \%<\Delta T_{1} \leq 60 \%\right](t, t+7)$, corresponding to moderate damage, in the cases of the $\mathrm{C} 1 \mathrm{~L}$ and $\mathrm{C} 1 \mathrm{M}$ lowcode building models in Scenarios 1 and 2. In all cases, this probability exceeds the tolerable risk thresholds after the mainshock, with 95\% confidence. These buildings are given a red tag with respect to moderate damage, as long as the 5th percentile of $P\left[40 \%<\Delta T_{1} \leq 60 \%\right](t, t+7)$ exceeds the considered tolerable threshold. Of all of the cases in Fig. 11, the C1L low-code model in Scenario 2 (Fig. 11b) is tagged red the longest with respect to moderate damage. This seems reasonable, as the mainshock in Scenario 2 has a larger magnitude and more aftershocks are expected and given that the C1L lowcode model has fragility curves with higher values [29] than the C1M lowcode model. According to Fig. 11b, the C1L low-code building model is tagged red with respect to $P\left[40 \%<\Delta T_{1} \leq 60 \%\right](t, t+7)$ for 2.9 days after the mainshock. This means that, over this period, moderate damage is forecasted for this building model, with $95 \%$ confidence.

Fig. 12 presents $P\left[40 \%<\Delta T_{1} \leq 60 \%\right](t, t+7)$ for the same models and scenarios included in Fig. 11. As in Fig. 11, the estimated probabilities for the C1L low-code model are higher than those for the C1M low-code model. Here, we focus on the duration of the orange tag, whose end signifies that the aftershock sequence is no longer a safety concern. Moreover, the duration of the orange tag reflects the amount of uncertainties considered. For both building models in Fig. 12, the duration of the orange tag is longer in Scenario 1. This may seem counterintuitive, as in Scenario 1 , the mainshock magnitude is smaller, and less aftershocks are expected. However, the mainshock in Scenario 1 is closer to the building, leading to higher uncertainty with respect to aftershock distances, the intensities of the aftershock ground motions, the estimated $P\left[40 \%<\Delta T_{1} \leq 60 \%\right](t, t+$
7), and, ultimately, the duration of the orange tag.

Finally, Tables 5 and 6 summarize the time after the mainshock for the buildings to switch from red to orange $\left(t_{\text {red }}\right)$ and from orange to green $\left(t_{\text {orange }}\right)$ for the four tolerable risk thresholds $\left(\lambda_{\text {toli }}, i=1-4\right)$ for Scenarios 1 and 2 , respectively. With respect to $\lambda_{\text {tol } 1}$, only the C1L and C2L models are tagged red for 0.1 days after the mainshock in Scenario 1. In Scenario 2 , the C2M model is tagged green after the mainshock based on $\lambda_{\text {tol1 }}$ owing to the lower vulnerability of this model. For performance levels corresponding to $\lambda_{\text {tol3 }}$ and $\lambda_{\text {tol4 }}$, all building models are tagged red immediately after the mainshock, i.e., the probability of moderate structural damage is intolerable at the beginning of Scenarios 1 and 2. In Scenario 2, for performance levels corresponding to $\lambda_{t o l 3}$ and $\lambda_{\text {tol }}$, the buildings remain red-tagged for longer after the mainshock, with the length of time increasing with fragility (e.g., 2.9 and 4.4 days for the C1L and C2L models for $\lambda_{\text {tol4 }}$, respectively). The most striking observation from the results is the length of the orange tag period in most cases for this tolerable risk threshold: for Scenarios 1 and 2, the orange tag period regarding moderate structural damage may exceed one year in certain cases.

\section{Conclusion}

In this study, we presented an operational framework to assess damage risk and its variation over time during a seismic crisis. Our objective was to develop an underlying probabilistic framework to be used as an emergency decision support tool with respect to the integrity of structures damaged during a mainshock-aftershocks sequence. The originality of this underlying framework is in the use of fragility curves for damage state thresholds in terms of period elongation as a proxy for damage. This allows the structural period measurements during seismic sequences [23, $24]$ to be used to define the initial state vector in the Markov chain computation and to update the forecasts.

The underlying probabilistic framework for the operational forecast of damage states is based on aftershock sequences for two mainshock scenarios in the vicinity of Thessaloniki. The operational earthquake forecasting during the aftershock sequences is provided by an ETAS model. The risk assessment is then completed by associating the spatiotemporal variation of the sequence's events with the probable structural damage and levels of performance considered in this study with respect to moderate damage or human life safety.

This study confirms the major contribution of the aftershocks to the risk associated with each scenario. In Scenario 2, the median probability of $\Delta T_{1}=60 \%$ at the end of the aftershock sequence is more than twice the median probability for the mainshock for all considered building models. In Scenario 1, this ratio is equal to 3.41 in the case of the C2M low-code building model. An original framework is also proposed for assessing risk for decision-making processes during seismic crises based on a physical parameter for characterizing the level of damage in the structures, rather than an empirical visual screening approach. It is worth noting that there is room for further reduction of uncertainty in the results, i.e., mainly in the duration of the orange classification. For example, in the case of the C1L low-code building model, the duration of the orange tag is 17.5 days 
with respect to the heavy damage state based on the tolerable risk threshold 2 . This uncertainty can be reduced by integrating more information on the seismic response of the structure, for example, by using higher modes or damping, by improving the levels of damage proportional to the period elongation, and particularly by selecting intensity measures as efficient and sufficient as possible in predicting the structure's response. In particular, spectral values (e.g., spectral velocity) for integrating the period elongation would significantly decrease the uncertainties [69].

In principle, the proposed framework is empirical. It uses measurements of period elongation before and after seismic events, rather than building modeling. The use of fragility curves by building type is common in decision-making during an earthquake crisis. In this context, generic building models were chosen to evaluate the fragility curves in terms of period elongation. Based on the measured period elongations at a given time, updated assessments for the remaining aftershock sequence can be performed. In that case, the assessments should use an initial state vector defined based on the measured elongation and the events in the synthetic aftershock catalogs after the time of the determination of the period elongation. The intent is to identify buildings that are considered unsafe once they exceed tolerable risk thresholds owing to all seismic events in a selected time window. The developed framework is different and complementary to existing building tagging operations, as discussed above.

The need for measurements is a sine qua non condition. This implies obtaining the periods of buildings before damage, or the more expensive option of using permanent instrumentation, which could be installed in certain critical structures. The continuous monitoring of the fundamental period during a seismic sequence can help assess the risk associated with vulnerability changes and the spatiotemporal distribution of the aftershocks. Based on the variations in the vulnerability and estimated probability of damage, characterizing buildings with respect to performance levels is possible (e.g., immediate occupancy, collapse prevention). In this case, a real-time online algorithm could be developed using a solution like that proposed by Guéguen and Tiganescu [72] based on the traffic light concept. False alarms would have to be considered by integrating natural period variations and the slow recovery of the elastic properties after a seismic event, as reported by Guéguen et al. [75] and Astorga et al. [21]. Such elements could be incorporated into the developed framework and used to support decision-making with respect to recovery time.

\section{Acknowledgements}

The authors thank Prof. Kyriazis Pitilakis of the Aristotle University of Thessaloniki for providing the details of the building models. Part of this work was supported by the harmonized approach to stress tests for critical infrastructures against natural hazards (STREST) project, funded by the EU Seventh Framework programme (Grant agreement No. 603389), and the Seismology and Earthquake Engineering Research Infrastructure Alliance for Europe (SERA) project, funded by the EU Horizon 2020 programme under Grant Agreement Number 730900.

\section{References}

[1] Bindi D, Iervolino I, Parolai S (2016) On-site structure-specific real-time risk assessment: perspectives from the REAKT project. Bulletin of Earthquake Enginering 14: 2471-93.

[2] Parolai S, Haas M, Pittore M, Fleming K (2018) Bridging the gap between seismology and engineering: towards real-time damage assessment. In: Pitilakis $\mathrm{K}$ (ed) Recent Advances in Earthquake Engineering in Europe, Vol. 46. Cham: Springer International Publishing; p. 253-61.

[3] Herrmann M, Douglas Zechar J, Wiemer S (2016) Communicating time-varying seismic risk during an earthquake sequence. Seismological Research Letters 87: 301-12.

[4] Chioccarelli E, Iervolino I (2016) Operational earthquake loss forecasting: a retrospective analysis of some recent Italian seismic sequences. Bulletin of Earthquake Engineering 14:2607-26.

[5] Li Q, Ellingwood BR (2007) Performance evaluation and damage assessment of steel frame buildings under main shock-aftershock earthquake sequences.
Earthquake Engineering and Structural Dynamics 36: 405-27.

[6] Burton HV, Sharma M (2017) Quantifying the reduction in collapse safety of main shock-damaged reinforced concrete frames with infills. Earthquake Spectra 33: 25-44.

[7] Iervolino I, Giorgio M, Chioccarelli E (2014) Closed-form aftershock reliability of damage-cumulating elastic-perfectly-plastic systems: aftershock reliability of elastic-perfectly-plastic systems. Earthquake Engineering and Structural Dynamics 43: 613-25.

[8] Shokrabadi M, Burton HV (2018) Risk-based assessment of aftershock and mainshock-aftershock seismic performance of reinforced concrete frames. Structural Safety 73: 64-74.

[9] Jalayer F, Ebrahimian H (2017) Seismic risk assessment considering cumulative damage due to aftershocks. Earthquake Engineering and Structural Dynamics 46: 369-89.

[10] Iervolino I, Giorgio M, Chioccarelli E (2016) Markovian modeling of seismic damage accumulation: Markovian Modeling of seismic damage accumulation Earthquake Engineering and Structural Dynamics 45: 441-61.

[11] Reuland Y, Lestuzzi P, Smith IFC (2019) A model-based data-interpretation framework for post-earthquake building assessment with scarce measurement data. Soil Dynamics and Earthquake Engineering 116: 253-63.

[12] Grimaz S, Malisan P (2017) How could cumulative damage affect the macroseismic assessment? Bulletin of Earthquake Engineering 15: 2465-81.

[13] Michel C, Zapico B, Lestuzzi P, Molina FJ, Weber F (2011) Quantification of fundamental frequency drop for unreinforced masonry buildings from dynamic tests. Earthquake Engineering and Structural Dynamics 40: 1283-96.

[14] Brun M, Labbe P, Bertrand D, Courtois A (2011) Pseudo-dynamic tests on lowrise shear walls and simplified model based on the structural frequency drift Engineering Structures 33: 796-812.

[15] Katsanos EI, Sextos AG, Elnashai AS (2014) Prediction of inelastic response periods of buildings based on intensity measures and analytical model parameters. Engineering Structures 71: 161-77.

[16] Katsanos EI, Sextos AG (2015) Inelastic spectra to predict period elongation of structures under earthquake loading: inelastic spectra for period elongation of structures. Earthquake Engineering and Structural Dynamics 44: 1765-82.

[17] Masi A, Vona M (2010) Experimental and numerical evaluation of the fundamental period of undamaged and damaged RC framed buildings. Bulletin of Earthquake Engineering 8: 643-56.

[18] Norouzi A, Poursha M (2018) The collapse period of degrading SDOF systems considering a broad range of structural parameters. Soil Dynamics and Earthquake Engineering 115: 730-41.

[19] Raghunandan M, Liel AB, Luco N (2015) Aftershock collapse vulnerability assessment of reinforced concrete frame structures: aftershock collapse assessment of reinforced concrete structures. Earthquake Engineering and Structural Dynamics 44: 419-39.

[20] Clinton JF (2006) The observed wander of the natural frequencies in a structure. Bulletin of the Seismological Society of America 96: 237-57.

[21] Astorga A, Guéguen P, Kashima T (2018) Nonlinear elasticity observed in buildings during a long sequence of earthquakes. Bulletin of the Seismological Society of America 108: 1185-98.

[22] Gallipoli MR, Stabile TA, Guéguen P, Mucciarelli M, Comelli P, Bertoni M (2016) Fundamental period elongation of a RC building during the Pollino seismic swarm sequence. Case Studies in Structural Engineering 6: 45-52.

[23] Dunand F, Ait Meziane Y, Guéguen P, Chatelain J-L, Guillier B, Ben Salem R, et al (2001) Utilisation du bruit de fond pour l'analyse des dommages des bâtiments de Boumerdes suite au séisme du 21 mai 2003. Memoires du Service Geologique Algerien 12: 177-91.

[24] Vidal F, Navarro M, Aranda C, Enomoto T (2014) Changes in dynamic characteristics of Lorca RC buildings from pre- and post-earthquake ambient vibration data. Bulletin of Earthquake Engineering 12: 2095-110.

[25] Kagan YY, Knopoff L (1987) Statistical short-term earthquake prediction. Science 236: 1563-7.

[26] Ogata Y (1988) Statistical models for earthquake occurrences and residual analysis for point processes. Journal of the American Statistical Association 83: 9-27.

[27] Kagan YY, Jackson DD (2000) Probabilistic forecasting of earthquakes. Geophysical Journal International 143: 438-53.

[28] Chioccarelli E, Iervolino I (2012) Part 2 (AMRA - Multiple shock capacity reduction for non-evolutionary structural systems). D41 Fragility Funct. - Impact Repeated Events Var. Intensities Fragility Funtions Build. Typology Local Scale MATRIX - New Methodol. Multi-Hazard Multi-Risk Assess. Methods Eur.

[29] Trevlopoulos K, Guéguen P (2016) Period elongation-based framework for operative assessment of the variation of seismic vulnerability of reinforced concrete buildings during aftershock sequences. Soil Dynamics and Earthquake Engineering 84: 224-37. 
[30] Marzocchi W, Lombardi AM, Casarotti E (2014) The establishment of an operational earthquake forecasting system in Italy. Seismological Research Letters 85: 961-9.

[31] Pagani M, Monelli D, Weatherill G, Danciu L, Crowley H, Silva V, et al. (2014) OpenQuake engine: an open hazard (and risk) software for the global earthquake model. Seismological Research Letters 85: 692-702.

[32] Pitilakis K, Woessner J, Valensise G, Arvidsson R, Giardini D, Sesetyan K, et al. (2013) Seismic Hazard Harmonization in Europe (SHARE): Online Data Resource. https://doi.org/10.12686/SED-00000001-SHARE.

[33] The SHARE Consortium, Woessner J, Laurentiu D, Giardini D, Crowley H, Cotton F, et al. (2015) The 2013 European Seismic Hazard Model: key components and results. Bulletin of Earthquake Engineering 13: 3553-96.

[34] Papazachos B, Mountrakis D, Psilovikos A, Leventakis G (1979) Surface fault traces and fault plane solutions of the May-June 1978 major shocks in the Thessaloniki area, Greece. Tectonophysics 53: 171-83.

[35] Mountrakis D, Tranos M, Papazachos C, Thomaidou E, Karagianni E, Vamvakaris D (2006) Neotectonic and seismological data concerning major active faults, and the stress regimes of Northern Greece. Geological Society of London Special Publications 260: 649-70.

[36] Papaioannou ChA (2000) Time-independent and time-dependent seismic hazard in greece based on seismogenic sources. Bulletin of the Seismological Society of America 90: 22-33.

[37] Koravos G (2003) Assessment of seismic hazard in Greece and surrounding regions using a design earthquake model. Doctoral dissertation, Aristotle University of Thessaloniki (in Greek).

[38] Helmstetter A (2006) Comparison of short-term and time-independent earthquake forecast models for Southern California. Bulletin of the Seismological Society of America 96: 90-106.

[39] Papazachos B, Comninakis P, Karakaisis G, Karakostas B, Papaioannou C, Papazachos C, et al. (2000) A catalogue of earthquakes in Greece and surrounding area for the period 550BC-1999. University of Thessaloniki. Thessaloniki. Greece: Aristotle University of Thessaloniki.

[40] Papazachos B, Comninakis P, Scordilis E, Karakaisis G, Papazachos C (n.d.) A catalogue of earthquakes in the Mediterranean and surrounding area for the period 1901 - 2010. Thessaloniki, Greece: Aristotle University of Thessaloniki.

[41] Aristotle University Of Thessaloniki Seismological Network. Permanent Regional Seismological Network operated by the Aristotle University of Thessaloniki 1981. https://doi.org/10.7914/SN/HT.

[42] Helmstetter A, Sornette D (2002) Subcritical and supercritical regimes in epidemic models of earthquake aftershocks: epidemic models of earthquake aftershocks. Journal of Geophysical Research Solid Earth 107. https://doi.org/10.1029/2001JB001580. ESE 10-1-ESE 10-21.

[43] Helmstetter A, Sornette D (2002) Diffusion of epicenters of earthquake aftershocks, Omori's law, and generalized continuous-time random walk models. Physical Reviwe E 66. https://doi.org/10.1103/PhysRevE.66.061104.

[44] Hainzl S, Christophersen A, Enescu B (2008) Impact of earthquake rupture extensions on parameter estimations of point-process models. Bulletin of the Seismological Society of America 98: 2066-72.

[45] Helmstetter A (2005) Importance of small earthquakes for stress transfers and earthquake triggering. Journal of Geophysical Research 110 https://doi.org/10.1029/2004JB003286.

[46] Kappos AJ, Panagopoulos G, Panagiotopoulos C, Penelis G (2006) A hybrid method for the vulnerability assessment of R/C and URM buildings. Bulletin of Earthquake Engineering 4: 391-413.

[47] Federal Emergency Agency. HAZUS-MH 2.1 Technical Manual. Washington, DC: Department of Homeland Security; n.d.

[48] Earthquake Planning and Protection (2001) EAK 2000 - Greek Antiseismic Code 2000 (in Greek). Athens, Greece.

[49] Mazzoni S, McKenna F, Scott M, Fenves G (2009) Open system for earthquake engineering simulation - user manual. Berkeley, CA: Pacific Earthquake Engineering Research Center.

[50] Filippou FC, Bertero VV, Popov EP (1983) Effects of bond deterioration on hysteretic behavior of reinforced concrete joints.

[51] Mander JB, Priestley MJN, Park R (1988) Theoretical stress-strain model for confined concrete. Journal of Structural Engineering 114: 1804-26.
[52] Kolozvari K, Orakcal K, Wallace JW (2015) Modeling of cyclic shear-flexure interaction in reinforced concrete structural walls. I: theory. Journal of Structural Engineering 141: 04014135.

[53] Karapetrou S, Manakou M, Bindi D, Petrovic B, Pitilakis K (2016) “Time-building specific" seismic vulnerability assessment of a hospital RC building using field monitoring data. Engineering Structures 112: 114-32.

[54] Code for interventions, 2nd revision (2017) Athens, Greece: Earthquake Planning and Protection.

[55] Kappos AJ (2013) Seismic Vulnerability and Loss Assessment for Buildings in Greece. In: Gueguen P (ed) Seismic Vulnerability of Structures, Hoboken, NJ, USA: John Wiley \& Sons, Inc., p. 111-60.

[56] Ricci P, De Risi MT, Verderame GM, Manfredi G (2013) Influence of infill distribution and design typology on seismic performance of low- and mid-rise RC buildings. Bulletin of Earthquake Engineering 11: 1585-616.

[57] Mackie K, Stojadinovic B. Seismic Demands of Performance-Based Design of Bridges. Berkeley, CA: Pacific Earthquake Engineering Research Center; n.d.

[58] SeismoArtif. SeismoSoft; n.d.

[59] Halldorsson B (2005) Calibration of the specific barrier model to earthquakes of different tectonic regions. Bulletin of the Seismological Society of America 95: $1276-300$.

[60] Ambraseys NN, Simpson KA, Bommer JJ (1996) Rrediction of horizontal response spectra in Europe. Earthquake Engineering and Structural Dynamics 25: 371-400.

[61] Pitilakis KD, Karapetrou ST, Fotopoulou SD (2014) Consideration of aging and SSI effects on seismic vulnerability assessment of RC buildings. Bulletin of Earthquake Engineering 12: 1755-76.

[62] Kappos AJ, Panagopoulos G (2010) Fragility curves for reinforced concrete buildings in Greece. Structure and Infrastructure Engineering 6: 39-53.

[63] Marasco S, Zamani Noori A, Cimellaro GP (2017) Cascading hazard analysis of a hospital building. Journal of Structural Engineering 143: 04017100.

[64] Polese M, Di Ludovico M, Prota A, Manfredi G (2013) Damage-dependent vulnerability curves for existing buildings: damage-dependent vulnerability curves for existing buildings. Earthquake Engineering and Structural Dynamics 42: 853-70.

[65] Di Ludovico M, Polese M, Gaetani d'Aragona M, Prota A, Manfredi G (2013) A proposal for plastic hinges modification factors for damaged RC columns. Engineering Structures 51: 99-112.

[66] Carrillo J (2015) Damage index based on stiffness degradation of low-rise RC walls: damage index based on stiffness degradation of low-rise RC walls. Earthquake Engineering and Structural Dynamics 44: 831-48.

[67] Carrillo J, Vargas D, Sánchez M (2018) Stiffness degradation model of thin and lightly reinforced concrete walls for housing. Engineering Structures 168: 17990.

[68] Luco N, Cornell CA (2007) Structure-specific scalar intensity measures for nearsource and ordinary earthquake ground motions. Earthquake Spectra 23: 35792.

[69] Perrault M, Guéguen P (2015) Correlation between ground motion and building response using California earthquake records. Earthquake Spectra 31: 202746.

[70] Iervolino I (2017) Assessing uncertainty in estimation of seismic response for PBEE. Earthquake Engineering and Structural Dynamics 46: 1711-23.

[71] Zentner I (2017) A general framework for the estimation of analytical fragility functions based on multivariate probability distributions. Structural Safety 64: 54-61.

[72] Guéguen P, Tiganescu A (2018) Consideration of the effects of air temperature on structural health monitoring through traffic light-based decision-making tools. Shock and Vibration 2018: 1-12.

[73] Silva V, Crowley H, Bazzurro P (2016) Exploring risk-targeted hazard maps for Europe. Earthquake Spectra 32: 1165-86.

[74] Comité Européen de Normalisation. Eurocode - Basis of structural design. EN 1990:2002. n.d.

[75] Guéguen P, Johnson P, Roux P (2016) Nonlinear dynamics induced in a structure by seismic and environmental loading. The Journal of the Acoustic Society of America 140: 582-90. 